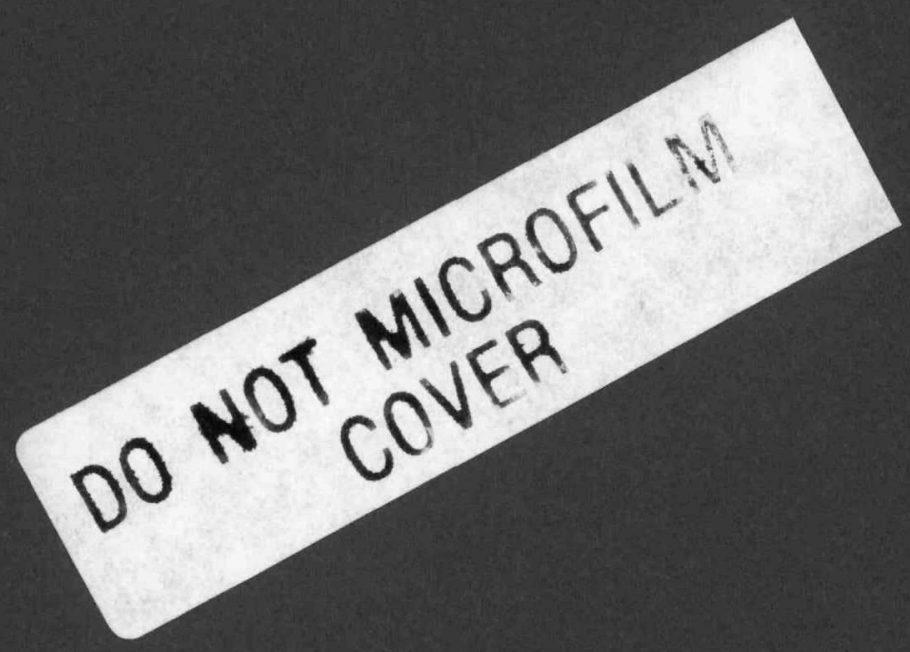

General-Purpose Heat Source Development: Safety Verification Test Program Flyer Plate Test Series 


\section{DISCLAIMER}

This report was prepared as an account of work sponsored by an agency of the United States Government. Neither the United States Government nor any agency Thereof, nor any of their employees, makes any warranty, express or implied, or assumes any legal liability or responsibility for the accuracy, completeness, or usefulness of any information, apparatus, product, or process disclosed, or represents that its use would not infringe privately owned rights. Reference herein to any specific commercial product, process, or service by trade name, trademark, manufacturer, or otherwise does not necessarily constitute or imply its endorsement, recommendation, or favoring by the United States Government or any agency thereof. The views and opinions of authors expressed herein do not necessarily state or reflect those of the United States Government or any agency thereof. 


\section{DISCLAIMER}

Portions of this document may be illegible in electronic image products. Images are produced from the best available original document. 


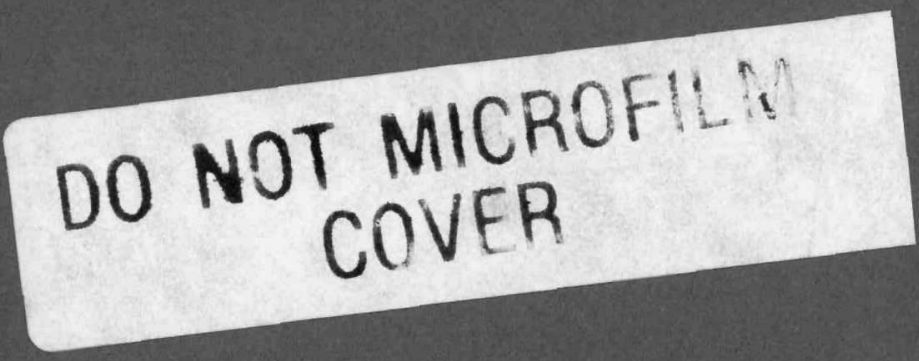

This work was supported by the US Department of Energy, Office of Special Nuclear Projects.

Edited by Renate Lewin

Photocomposition by E. Katherine Valdez

This report was prepared as an account of work sponsored by an agency of the United States Government. Neither the United States Government nor any agency thereof, nor any of their employees, makes any warranty, express or implied. or assumes any legal liability or responsibility for the accuracy, completeness, or usefulness of any information, apparatus, product, or process disclosed, or represents that its use would not infringe privately owned rights. Reference herein to any specific commercial product, process, or service by trade name, trademark, manufacturer, or otherwise. does not necessarily constitute or imply its endorsement, recommendation, or favoring by the United States Government or any agency thereof. The views and opinions of authors expressed herein do not necessarily state or reflect those of the United States Government or any agency thereof 


\title{
General-Purpose Heat Source Development: Safety Verification Test Program Flyer Plate Test Series
}

\author{
T. A. Cull
}

D. Pavone

\section{DISCLAIMER}

This report was prepared as an account of work sponsored by an agency of the United States Government. Neither the United States Government nor any agency thereof, nor any of their employees, makes any warranty, express or implied, or assumes any legal liability or responsibility for the accuracy, completeness, or usefulness of any information, apparatus, product, or process disclosed, or represents that its use would not infringe privately owned rights. Reference herein to any specific commercial product, process, or service by trade name, trademark, manufacturer, or otherwise does not necessarily constitute or imply its endorsement, recommendation, or favoring by the United States Government or any agency thereof. The views and opinions of authors expressed herein do not necessarily state or reflect those of the United States Government or any agency thereof.

\section{MASTER}

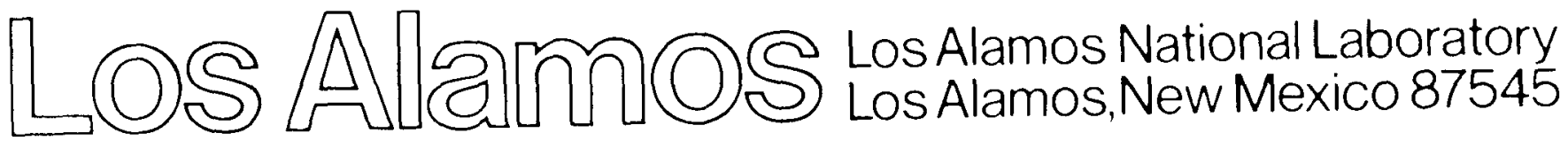




\title{
GENERAL-PURPOSE HEAT SOURCE DEVELOPMENT: SAFETY VERIFICATION TEST PROGRAM
}

\author{
Flyer Plate Test Series \\ by \\ T. A. Cull and D. Pavone
}

\begin{abstract}
The General-Purpose Heat Source (GPHS) is a modular component of a radioisotope thermoelectric generator (RTG) that will provide electric power for space missions. The initial RTG applications will be for the NASA Galileo and the ESA Ulysses missions. Each of the 18 GPHS modules in an RTG contains four ${ }^{238} \mathrm{PuO}_{2}$ fueled clads and generates $250 \mathrm{~W}_{(\mathrm{t})}$. A series of Safety Verification Tests (SVTs) has been conducted to assess the ability of the GPHS fueled clads to contain the plutonia in accident environments. Because a launch pad or postlaunch explosion of the Space Transportation System Vehicle (space shuttle) is one conceivable accident, the SVT plan included a series of tests to simulate the fragment environment that the RTG and GPHS modules would experience in such an event. These tests deal specifically with the flat-on collision of flyer-plate-type fragments with bare, simulant-fueled (depleted $\mathrm{UO}_{2}$ ) clads. Results of these tests suggest that the fueled clad is only minimally breached by collision with 3.53-mm-thick flyer-plate-type fragments of space shuttle alloy at velocities up to $1170 \mathrm{~m} / \mathrm{s}$. However, collision of a 38.1-mm-thick plate with a bare GPHS clad, at a velocity of $270 \mathrm{~m} / \mathrm{s}$, results in a total release of fuel.
\end{abstract}

\section{INTRODUCTION}

The General-Purpose Heat Source (GPHS) is a modular component of a radioisotope thermoelectric generator (RTG) that will provide power for space missions. The first two flights will be the NASA Galileo and the ESA Ulysses (formerly International SolarPolar) missions. The RTG provides electric power by using the heat of ${ }^{238} \mathrm{Pu} \alpha$-decay to create a temperature differential across a thermoelectric array. The Galileo spacecraft will use two RTGs and the Ulysses will use a single RTG. Each RTG contains 18 GPHS modules.

A GPHS module contains four ${ }^{238} \mathrm{PuO}_{2}$-fueled clads and provides a total thermal output of $250 \mathrm{~W}_{(\mathrm{t})}$ at the beginning of life. Each fueled clad consists of a ${ }^{238} \mathrm{PuO}_{2}$ fuel pellet encapsulated in an iridium-alloy $(0.3 \%$ tungsten) containment shell. Two fueled clads are held in a
Fineweave-Pierced Fabric* (FWPF) graphite impact shell (GIS), and two GISs are contained within an FWPF aeroshell (Fig. 1). One of the goals of the GPHS module design was to minimize the release of plutonia in an accident environment.

In the Galileo and Ulysses missions, a liquid-fueled Centaur rocket will be transported with each spacecraft in the cargo bay of the Space Transportation System Vehicle (space shuttle). An Air Force Rocket Propulsion Laboratory analysis indicates that a launch explosion, fueled by the shuttle and Centaur propellants, would expose the RTG and GPHS modules to high overpressures and to a field of space shuttle alloy fragments. ${ }^{1}$

*Fineweave-Pierced Fabric 3-D carbon/carbon composite, a product of AVCO Systems Division, 201 Lowell St., Wilmington, MA 01887. 


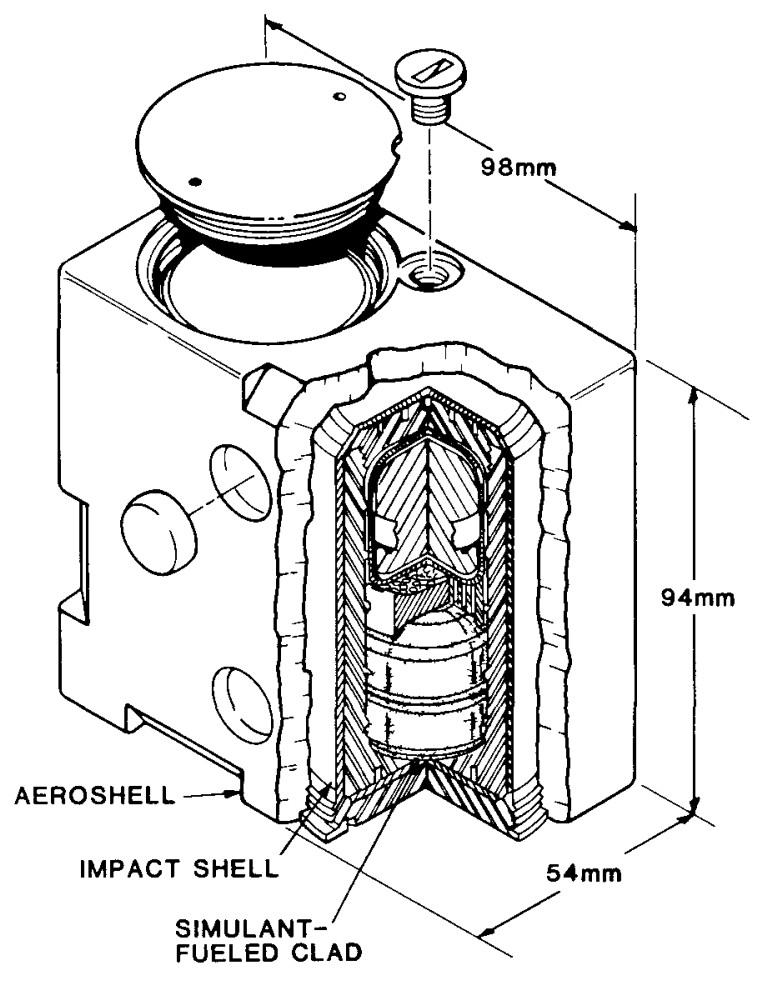

Fig. 1. Each GPHS module contains four ${ }^{238} \mathrm{PuO}_{2}$ fueled capsules.

Therefore, the Safety Verification Test (SVT) plan included a series of tests to determine the response of the fueled clads to such an environment. ${ }^{2}$

\section{THE TEST PROGRAM}

The flyer plate tests (FPTs) simulated the flat-on collision of flyer-plate-type fragments that the ${ }^{238} \mathrm{PuO}_{2}$ containing GPHS fueled clads could experience in a launch explosion. Bare clads were tested under the assumption that such an explosion would strip the GPHS module of its graphite components.
Four FPTs were conducted. In the first three tests, the plate thickness was equivalent (mass-averaged) to a flyer plate derived from the major structures involved in Centaur and shuttle external tank explosions as defined in the Shuttle Data Book. ${ }^{3}$ The plate thickness was constant, but we varied the velocity from about $350 \mathrm{~m} / \mathrm{s}$ to $1170 \mathrm{~m} / \mathrm{s}$ to determine the minimum velocity that would cause a substantial fuel release. In FPT-4, the plate thickness was significantly increased to represent the thickness of a forward bulkhead fragment, but the velocity was reduced to about $270 \mathrm{~m} / \mathrm{s}$. In all of the tests, the fueled clad orientation was vertical (vent end up), and the plate orientation was flat-on.

\section{A. Components}

In each test, the test assembly consisted of a simulantfueled clad and an aluminum-alloy flyer plate. A simulant fuel of sintered uranium dioxide (depleted $\mathrm{UO}_{2}$ ) was used because the facility was not equipped to contain plutonium oxide. The bulk density of each $\mathrm{UO}_{2}$ pellet was adjusted to match the mass and configuration of an average plutonia fuel pellet. The iridium-alloy containment shells were flight-quality units provided by the Mound Facility. Los Alamos National Laboratory fabricated the $\mathrm{UO}_{2}$ pellets, which were encapsulated in containment shells at the Savannah River Laboratory. Data describing the iridium and $\mathrm{UO}_{2}$ components are presented in Table I.

The fueled clads in the first three tests had been exposed to an estimated $3.45 \mathrm{MPa}$ (500 psi) overpressure in the sixth shock tube overpressure test (CST-6-RTG-2). ${ }^{4}$ The overpressure hydrostatically compressed the clads around the fuel pellets, reducing the gap between components. Each of the clads experienced slight deformation as indicated by the maximum:minimum $(\mathrm{M} / \mathrm{m})$ diameter ratios in Table $\mathrm{I}$. The fueled clad in FPT-4 had no previous overpressure exposure.

In each test, the flyer plate was a $15.24-\times 17.78-\mathrm{cm}$ aluminum-alloy (2024-T6) plate (Table II). The average microhardness of the plate was $171 \mathrm{VHN}$ at 200-g load.

Table I. Iridium and $\mathrm{UO}_{2}$ Test Components Used in GPHS Flyer Plate Tests

\begin{tabular}{|c|c|c|c|c|c|c|c|}
\hline \multirow[b]{2}{*}{ Test } & \multirow[b]{2}{*}{ Capsule } & \multicolumn{2}{|c|}{ Iridium Clad } & \multirow[b]{2}{*}{$\mathrm{UO}_{2}$ Pellet } & \multirow{2}{*}{$\begin{array}{c}\text { Fueled Capsule } \\
\text { Weight (g) }\end{array}$} & \multirow{2}{*}{$\begin{array}{l}\text { Estimated } \\
\text { Previous } \\
\text { Exposure }\end{array}$} & \multirow[b]{2}{*}{ M/m Ratio ${ }^{\mathbf{a}}$} \\
\hline & & Vent Cup & Blind Cup & & & & \\
\hline FPT-1 & M-10 & Z531-3 & Z533-5 & 85-11 & 202.434 & 500 psi & 1.033 \\
\hline FPT-2 & М-9 & Z523-5 & Z533-3 & 85-10 & 205.648 & $500 \mathrm{psi}$ & 1.048 \\
\hline FPT -3 & M-12 & Z527-3 & $\mathrm{Z512-4}$ & $85-13$ & 202.019 & 500 psi & 1.011 \\
\hline FPT-4 & M-33 & Z561-1 & Z559-2 & $85-33$ & 206.807 & None & $\mathbf{N} / \mathbf{A}$ \\
\hline
\end{tabular}


Table II. Flyer Plate Chemical Analyses

\begin{tabular}{cccc}
\hline & \multicolumn{3}{c}{ Weight Percent } \\
\cline { 2 - 4 } Element & EMP Analysis $^{\mathrm{a}}$ & ICP Analysis $^{\mathrm{b}}$ & Nominal \\
\hline Al & 93.3 & 94.0 & 93.4 \\
Cu & 4.40 & 3.93 & 4.50 \\
Mn & 0.60 & 0.50 & 0.60 \\
Mg & 1.44 & 1.31 & 1.50
\end{tabular}

a Electron microprobe analysis.

bInductively coupled plasma analysis.

A plate thickness of $3.53 \mathrm{~mm}$ was used in the first three tests, and a thickness of $38.1 \mathrm{~mm}$ was used in FPT-4.

\section{B. Equipment and Procedures}

All of the flyer plate tests were conducted at Sandia National Laboratories' (SNLA) Coyote III Test Area in Albuquerque, New Mexico. SNLA was responsible for charge calculation, fabrication and detonation, flash $\mathrm{x}$-ray setup and operation, and plate velocity calculations. Los Alamos was responsible for test section assembly and operation, flyer plate fabrication, and posttest recovery and analysis.

Tests were conducted in a steel shock tube section that had been modified so that the sample could be heated in an inert atmosphere and the flyer plate/charge assembly and the sample could be remotely positioned for the test. The fueled clad was heated so that its temperature at impact was $1091^{\circ} \mathrm{C}$, the launch temperature of clads in an on-pad RTG. The completed test assembly, consisting of the fueled clad and the flyer plate, was contained in the $55.88-\mathrm{cm}$-i.d., $175-\mathrm{cm}$-long test section (Fig. 2) with 38.1-cm-i.d. upper and lower chambers. A furnace insulated with alumina, Marinite, and Fiberfrax Durablanket* insulation was suspended in the upper chamber, and an air cylinder with a set of graphite insulating blocks attached to the piston end was bolted to the lower chamber. The fueled clad was placed, vent end up, on a FWPF graphite support. A 6.35-mm FWPF graphite set screw applied pressure downward on the vent end to hold the clad in place. The support and the fueled clad were then attached with a $12.7-\mathrm{mm}$ FWPF graphite screw to a removable furnace base, which rested on the top graphite insulating block. The fueled clad could be raised and lowered remotely with the air cylinder.

In the first three tests, the flyer plate was placed in a $30.5-\times 81.3-\mathrm{cm}$ plywood frame, and the charge was attached to it. An electric winch, which was mounted on the top of the test section, was used to remotely lower the flyer plate/charge assembly through a 3.81 -cm-wide slot into the test section. The flyer plate/charge assemblies in the first three tests were not placed in the pretest position and attached to the winch cable until fueled clad heating was near completion. This lessened

*Fiberfrax Durablanket insulation, a product of Carborundum Company, Insulation Division, P.O. Box 808, Niagra Falls, NY 14302.
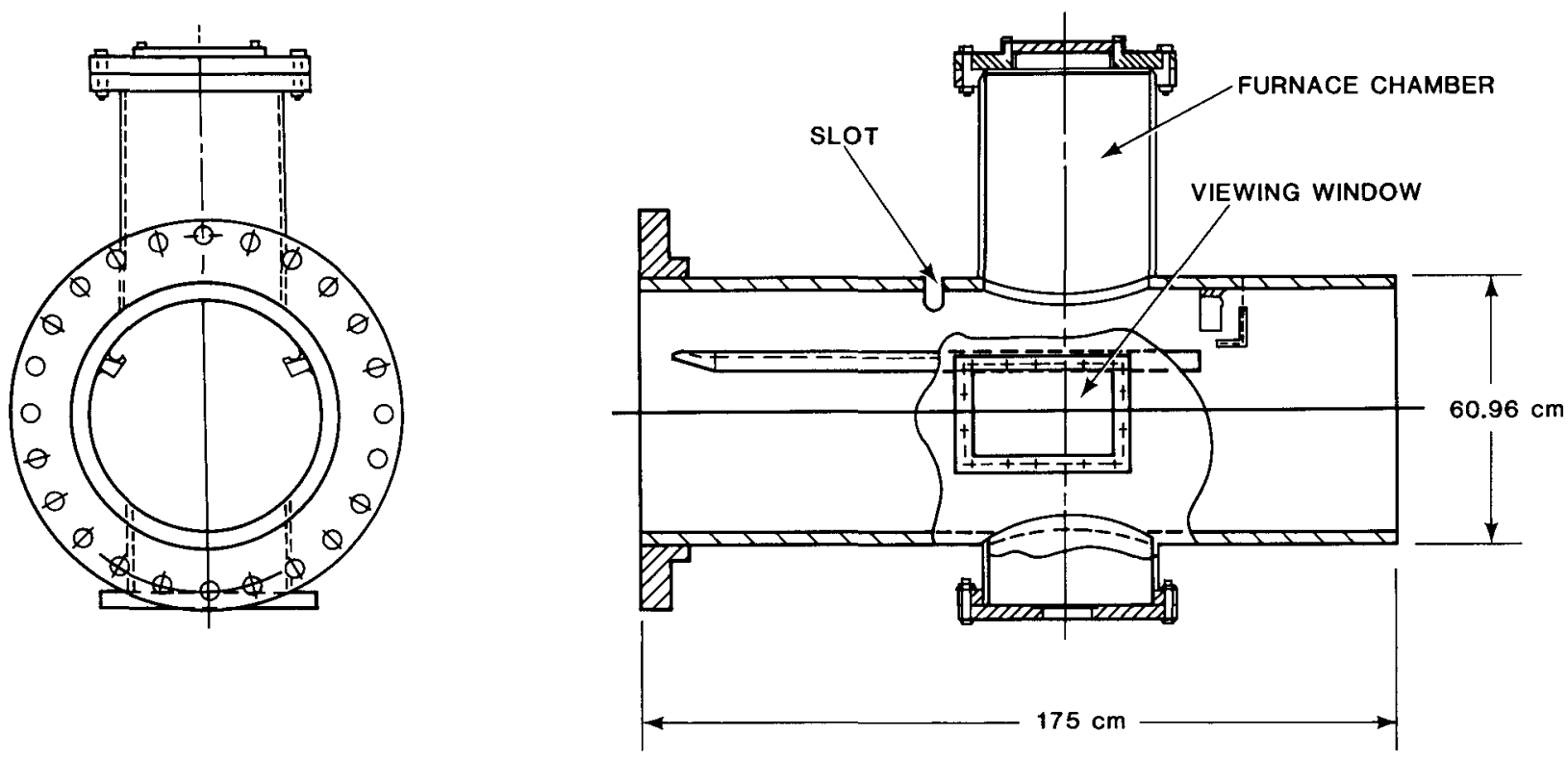

Fig. 2. The test assembly was contained in a steel test section. 
the possibility of assembly degradation by the hightemperature source (furnace) nearby. In FPT-4, the flyer plate/charge assembly was placed inside the test section, $1.27 \mathrm{~cm}$ from an aluminum foil/plywood frame located at the inside edge of the furnace chamber, when heating was near completion. Degradation of the assembly by the furnace heat was less likely in this test because the plywood frame and aluminum foil provided some protection from the radiant heat.

A 27.9- $\times 38.1-\mathrm{cm}$ window was located on each side of the test section. Two flash $\mathrm{x}$-ray units were positioned at the center of the windows to provide data of the flyer plate in flight. One window was sealed with a $1.27-\mathrm{cm}-$ thick Lexan plate and the other was covered with a 0.32 cm-thick aluminum sheet. A $38.1-\mathrm{cm}$-i.d. cardboard catch tube filled with sawdust was placed at the exit end of the test section. The test setup is shown in Figs. 3 and 4.

Before the actual flyer plate tests could be conducted, calibration tests were conducted to determine the amount of heat the fueled clad would lose during an 8-s unheated transition period from the furnace to the test position. We used a manual optical pyrometer to measure the fueled clad temperature at the test position and at 10-s intervals after the first reading. Results from this test (Table III) had indicated that an initial clad temperature of $1200^{\circ} \mathrm{C}$ would result in a test temperature of about $1091^{\circ} \mathrm{C}$ at impact. However, after the first two FPTs, we conducted a second set of calibration tests using an automatic optical pyrometer, because we were concerned about the reliability of the measurements made with the manual instrument. These measurements (Table IV), recorded at 4-s intervals, indicated that an initial temperature of $1250^{\circ} \mathrm{C}$ is required to achieve a test temperature of $1091^{\circ} \mathrm{C}$.

In the first three FPTs, we sealed the test section ends with aluminum foil and plastic and initiated a continuous nitrogen gas flow to the furnace and test section before heating the fueled clad. In FPT-4, we used a plywood frame, in which aluminum foil covered the expected flyer plate path, to seal the charge end of the test section at the inside edge of the furnace chamber. The exit end was sealed with plastic.

The air cylinder, with the piston extended, held the fueled clad in the furnace during heating. Temperature was measured by two type- $K$ thermocouples suspended in the furnace about $1.3 \mathrm{~cm}$ from each side of the simulant clad. When the clad temperature in all tests

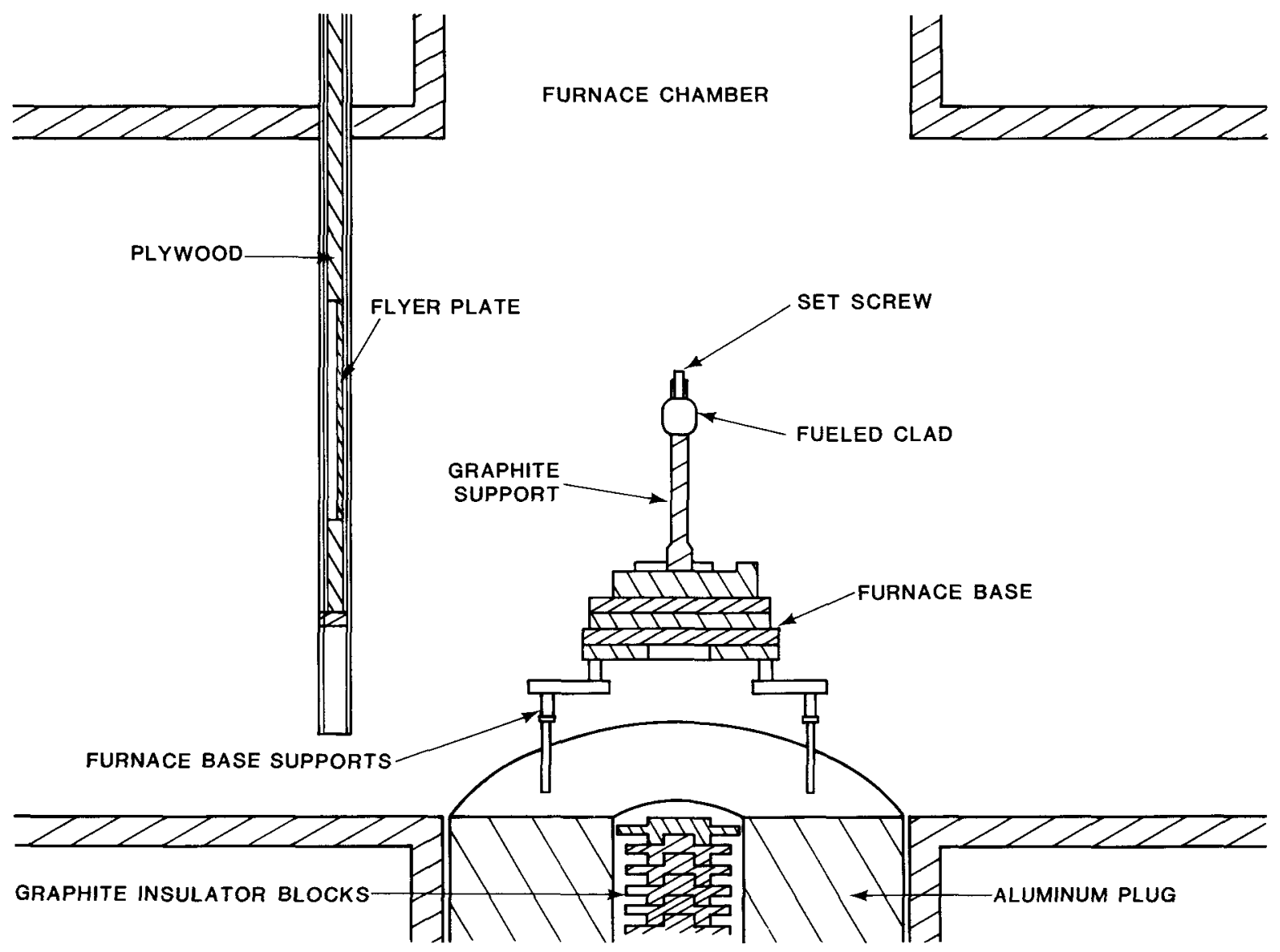

Fig. 3. Flyer plate test setup, section view. 


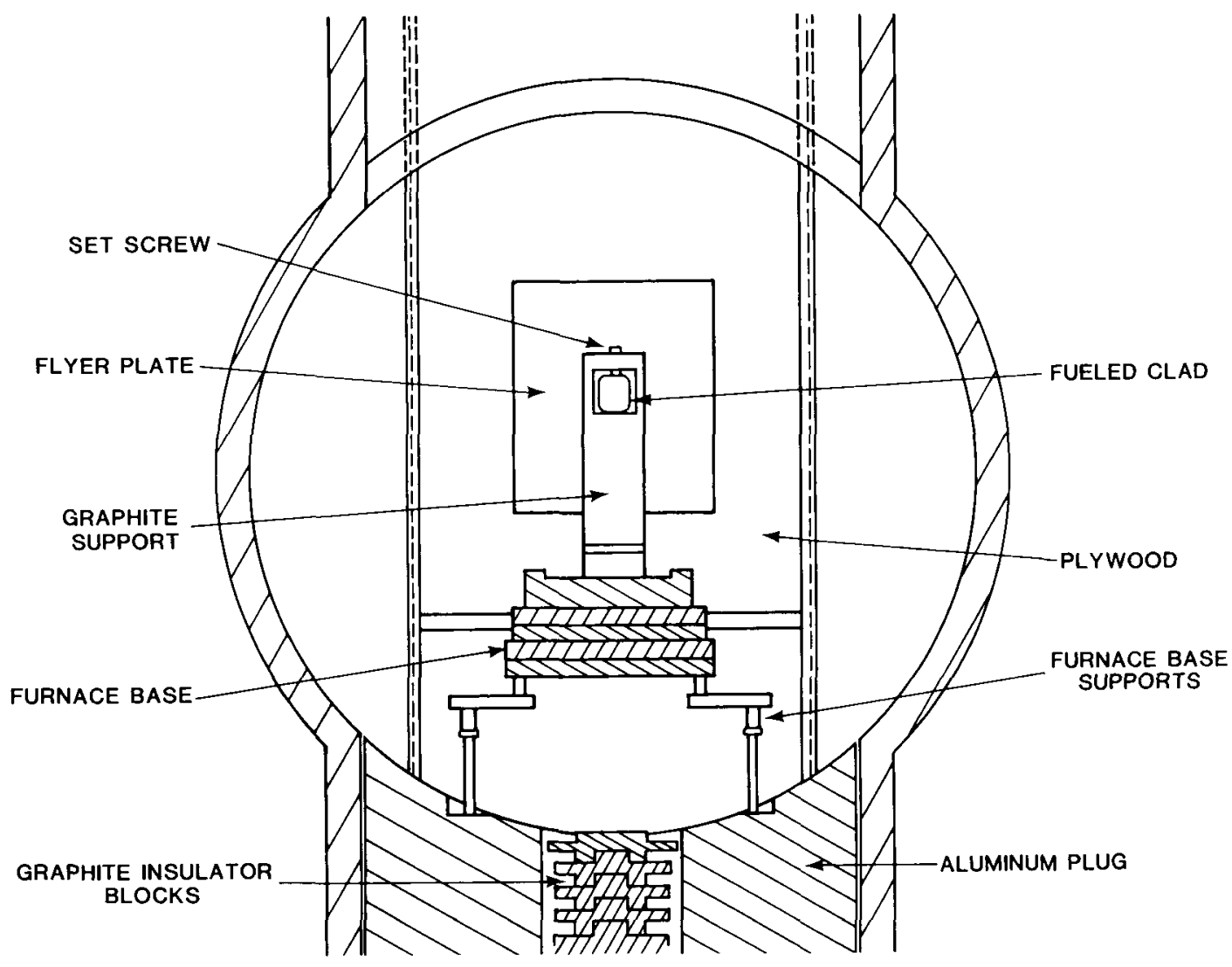

Fig. 4. Flyer plate test setup, end view.

\begin{tabular}{ccccccc}
\hline \hline Table III. Results of Temperature Calibration Test with Manual Optical Pyrometer \\
\hline \multicolumn{2}{c}{$\begin{array}{c}\text { Initial } \\
\text { Clad Temp } \\
\left({ }^{\circ} \mathrm{C}\right)\end{array}$} & $\begin{array}{c}\text { Transit Time to } \\
\text { Test Position } \\
(\mathbf{s})\end{array}$ & $\begin{array}{c}\text { Clad Temp at } \\
\text { Test Position } \\
\left({ }^{\circ} \mathrm{C}\right)\end{array}$ & $\begin{array}{c}\text { Clad Temps after Reaching } \\
\text { Test Position } \\
\left({ }^{\circ} \mathrm{C}\right)\end{array}$ \\
\hline & & & & $+10 \mathrm{~s}$ & $+20 \mathrm{~s}$ & $+30 \mathrm{~s}$ \\
1 & 1200 & 8 & 1120 & 1060 & $\mathbf{1 0 2 0}$ & $\mathbf{9 8 0}$ \\
2 & 1220 & 8 & 1166 & 1030 & 970 & 930 \\
3 & 1150 & 8 & 1060 & 1000 & 950 & 890 \\
\hline \hline
\end{tabular}

\begin{tabular}{ccccccr}
\hline \hline Table IV. Results of Temperature Calibration Test with Automatic Optical Pyrometer \\
\hline $\begin{array}{c}\text { Initial } \\
\text { Clad Temp } \\
\left({ }^{\circ} \mathrm{C}\right)\end{array}$ & $\begin{array}{c}\text { Transit Time to } \\
\text { Test Position } \\
(\mathbf{s})\end{array}$ & $\begin{array}{c}\text { Clad Temp at } \\
\text { Test Position } \\
\left({ }^{\circ} \mathrm{C}\right)\end{array}$ & $\begin{array}{c}\text { Clad Temps after Reaching } \\
\text { Test Position } \\
\left({ }^{\circ} \mathrm{C}\right)\end{array}$ \\
\hline & & & & $+4 \mathrm{~s}$ & $+8 \mathrm{~s}$ & $+12 \mathrm{~s}$ \\
1 & 1209 & 7 & 1033 & $\mathbf{1 0 0 8}$ & 993 & $\mathbf{9 7 6}$ \\
2 & 1225 & 8 & 1059 & 1018 & 1000 & $\mathbf{9 8 5}$ \\
3 & 1251 & 8 & 1082 & 1036 & 1018 & 1003 \\
\hline \hline
\end{tabular}


reached $1200^{\circ} \mathrm{C}$, the power to the furnace was temporarily disconnected for personnel safety. In the first three FPTs, SNLA staff attached the flyer plate/charge assembly to the winch cable outside the test section, and in FPT -4 , they placed the assembly inside the test section. In all tests, the detonator was then attached, and the power to the furnace was reconnected after the area was cleared. Some additional heating of the fueled clad was necessary because it had cooled during placement of the flyer plate/charge assembly.

When clad temperature again reached $1200^{\circ} \mathrm{C}$ $\left(1250^{\circ} \mathrm{C}\right.$ in FPT -3 and $1220^{\circ} \mathrm{C}$ in FPT-4), the $\mathrm{x}$-ray units were charged from the bunker. In the first three FPTs, the flyer plate/charge assembly and the heated clad were then simultaneously lowered into test position from the bunker. However, in FPT-4 only the clad was lowered to the center of the test section because the flyer plate/charge assembly was already in position. The test position of the flyer plate/charge assembly in the first three FPTs was verified on a video monitor by viewing the actuation of the winch and the final position of the plywood frame. In all tests, a video camera, focusing through the Lexan window into the test section, verified the operation of the air cylinder and the proper test position of the heated clad. The explosive charge was detonated as soon as test readiness was verified (immediately after the clad was viewed in position), driving the plate into the fueled clad flat-on.

After each test, the power to the furnace was disconnected and the area was surveyed for any test article debris outside the catch tube. SNLA personnel recovered the $x$-ray film and calculated the actual flyer plate velocity from the two flyer plate exposures on the film. The sawdust in the catch tube was sifted through $6.35-\mathrm{mm}$ screens to recover the test article debris. Recovered items were visually examined, photographed, and transported to Los Alamos for postmortem examination. Each clad was again examined and photographed at Los Alamos. Breach areas were measured, and the simulant fuel was sized. Urania particle size data are listed in Table V. Specimens for metallographic examination were then cut from the impact face of the clad and the impacted area of the flyer plate.

\section{RESULTS}

The results of each FPT are summarized in Table VI. Details of the individual tests and postmortem examinations are given below.

\begin{tabular}{|c|c|c|c|c|}
\hline $\begin{array}{c}\text { Particle Size } \\
(\mu \mathrm{m})\end{array}$ & $\begin{array}{c}\text { FPT-1 (M-10) } \\
348.7 \mathrm{~m} / \mathrm{s} \\
\end{array}$ & $\begin{array}{c}\text { FPT-2 (M-9) } \\
623.9 \mathrm{~m} / \mathrm{s}\end{array}$ & $\begin{array}{c}\text { FPT-3 (M-12) } \\
1173 \mathrm{~m} / \mathrm{s}\end{array}$ & $\begin{array}{c}\text { FPT-4 (M-33) } \\
271.3 \mathrm{~m} / \mathrm{s}\end{array}$ \\
\hline+6000 & 0.7080 & 0.4588 & 0.6533 & No data \\
\hline$-6000+2000$ & 0.1323 & 0.2191 & 0.1307 & No data \\
\hline$-2000+841$ & 0.0915 & 0.1854 & 0.1153 & No data \\
\hline$-841+420$ & 0.0383 & 0.0738 & 0.0525 & No data \\
\hline$-420+177$ & 0.0193 & 0.0370 & 0.0285 & No data \\
\hline$-177+125$ & 0.0032 & 0.0067 & 0.0055 & No data \\
\hline$-125+74$ & 0.0030 & 0.0066 & 0.0048 & No data \\
\hline$-74+44$ & 0.0016 & 0.0034 & 0.0025 & No data \\
\hline$-44+30$ & 0.0009 & 0.0024 & 0.0017 & No data \\
\hline+20 & 0.0004 & 0.0013 & 0.0006 & No data \\
\hline$-20+10$ & 0.0005 & 0.0023 & 0.0009 & No data \\
\hline-10 & 0.0011 & 0.0031 & 0.0035 & No data \\
\hline $1.00(\max )$ & 0.000108 & 0.000215 & 0.000372 & No data \\
\hline $2.00(\max )$ & 0.000210 & 0.000195 & 0.000880 & No data \\
\hline $3.00(\max )$ & 0.000202 & 0.000230 & 0.000446 & No data \\
\hline $4.00(\max )$ & 0.000184 & 0.000321 & 0.000415 & No data \\
\hline $5.00(\max )$ & 0.000050 & 0.000261 & 0.000209 & No data \\
\hline $6.00(\max )$ & 0.000159 & 0.000361 & 0.000045 & No data \\
\hline 7.00 (max) & 0.000046 & 0.000382 & 0.000072 & No data \\
\hline $8.00(\max )$ & 0.000034 & 0.000143 & 0.000321 & No data \\
\hline $9.00(\max )$ & 0.000049 & 0.000305 & 0.000152 & No data \\
\hline $10.00(\max )$ & 0.000067 & 0.000697 & 0.000627 & No data \\
\hline
\end{tabular}




\begin{tabular}{|c|c|c|c|c|c|}
\hline Test & $\begin{array}{c}\text { Clad Temp } \\
\left({ }^{\circ} \mathrm{C}\right)\end{array}$ & $\begin{array}{l}\text { Plate Thickness } \\
(\mathrm{cm})\end{array}$ & $\begin{array}{l}\text { Plate Velocity } \\
(\mathrm{m} / \mathrm{s})\end{array}$ & $\begin{array}{c}\text { Breach Area } \\
\left(\mathrm{mm}^{2}\right)\end{array}$ & $\begin{array}{c}\text { Weight of } \\
\text { Released } \mathrm{UO}_{2} \\
\text { (g) }\end{array}$ \\
\hline FPT-1 & 1025 & 0.353 & $348.7 \pm 10.4$ & Microcracks & 0.017 \\
\hline FPT-2 & 1025 & 0.353 & $623.9 \pm 31.2$ & 25.3 & 0.325 \\
\hline FPT-3 & 1080 & 0.353 & $1173 \pm 60$ & $\begin{array}{c}2.7 \text { (primary) } \\
141 \text { (secondary) }\end{array}$ & 6.77 \\
\hline FPT-4 & 1050 & 3.81 & $271.3 \pm$ & N/A & $151.8(100 \%)$ \\
\hline
\end{tabular}

\section{A. Flyer Plate Test 1}

In the first test, the flyer plate collided with the heated $\left(1025 \pm 10^{\circ} \mathrm{C}\right)$ fueled clad at a velocity of $348.7 \pm 10.4$ $\mathrm{m} / \mathrm{s}$. The flyer plate was completely penetrated by its collision with the clad, which produced a punchout fragment from the plate (Fig. 5a) and fragmented the plate into seven pieces. Clad M-12 (Fig. 5b) was recovered $0.76 \mathrm{~m}$ deep in the catch tube. The clad was breached by a transverse crack on the vent end, cylinder-to-end transition radius, and by an axial crack in the vent cup wall. Numerous surface microcracks were also present at the edges of the flyer plate punchout area. We determined that $0.017 \mathrm{~g}$ of urania had been released, based on the difference between the pretest weight of the $\mathrm{UO}_{2}$ pellet and the weight of the $\mathrm{UO}_{2}$ recovered for particle size analysis.

A transverse cross section through the axial crack and an axial cross section through the vent end crack were metallographically examined. Figure 6 illustrates the location of the axial breach relative to the center of the impact face. The iridium microstructure at the site of the breach is shown in Fig. 7. The fracture mode is intergranular with no indication of ductility. In addition to this breach, two nonpenetrating cracks were observed on the cross section (Fig. 8). One crack originated at the exterior surface and penetrated about $50 \%$ of the wall thickness. The other crack, which originated at the interior surface, penetrated about $75 \%$ of the wall thickness. Both nonpenetrating cracks were intergranular with no indication of ductility.

Comparison microstructures at the center of the impact face and at about $90^{\circ}$ from this point are shown in Figs. 9 and 10. Grains at the center of the impact face, as compared with those at the edge, were not significantly distorted. The wall thickness probably appears greater at the impact face center because the cross-section plane was off normal to the cylinder axis, not because of deformation thinning at the face edge. The average grain size was 28 grains/thickness.

Examination of the axial section of the clad (Fig. 11) showed one crack (Fig. 12) completely penetrating the iridium wall. Another major crack (Fig. 13) originated on the external surface of the clad and penetrated $85 \%$ of the wall thickness. There were also several surface boundary cracks that originated in this area. All of the cracks were intergranular. Some grain elongation occurred axially along the impact face (Fig. 14).

The seven fragments of the flyer plate ranged in weight from 2.98 to $66.2 \mathrm{~g}$. A transverse section of the flyer plate punchout was chosen for metallographic examination. Figure 15 shows that about $50 \%$ of the plate thickness sheared in a direction approximately normal to the plane of the plate, and the remainder sheared at a sinall angle to this plane. Porosity occurred near the edges of the punchout, suggesting a tendency of the plate to split on a plane near the center.

A transverse section of the flyer plate punchout at the edge near the centerline is shown in Fig. 16. The elongated grain structure parallel to the plane of the plate suggests that the rolling direction of the plate was perpendicular to the axis of the fueled clad at impact. Examination of undeformed cross sections (Fig. 17) taken from the edge of the flyer plate (transverse and parallel to the fueled clad axis) showed that the microstructures were not the same in both directions and that the orientation was as inferred from the punchout metallography.

\section{B. Flyer Plate Test 2}

In the second test, the velocity of the flyer plate was increased to $623.9 \pm 31.2 \mathrm{~m} / \mathrm{s}$. The flyer plate was again completely penetrated as it collided with the heated $\left(1025 \pm 10^{\circ} \mathrm{C}\right)$ clad (Fig. $\left.18 \mathrm{a}\right)$, producing a punchout fragment from the plate (Fig. 18b) and fragmenting the plate into 10 pieces. Two axial cracks, with a total breach area of $25.3 \mathrm{~mm}^{2}$, occurred at the edges of the fueled clad (M-9) impact face. The clad was recovered at a sawdust depth of $1.14 \mathrm{~m}$. By comparing the pretest weight of the $\mathrm{UO}_{2}$ pellet and the weight of the $\mathrm{UO}_{2}$ recovered for particle size analysis, we determined that $0.325 \mathrm{~g}$ of simulant fuel was released. 
A transverse section through the iridium clad that included the smaller of the axial cracks was metallographically examined. The photomacrograph in Fig. 19 illustrates the location of the fracture relative to the center of the impact face. The iridium (Fig. 20) was fine grained and the fracture mode was intergranular. The width of the breach was nearly uniform across the wall thickness, so it is likely that the fracture resulted from tensile stresses. Comparative microstructures of the iridium at the impact face center and $90^{\circ}$ from the center are shown in Figs. 21 and 22. The grain structure was slightly elongated, and the thickness in the center was reduced by about $17 \%$. The iridium was very fine grained with about 34 grains/thickness.

The 10 fragments of the flyer plate ranged in weight from 5.39 to $67.58 \mathrm{~g}$. Metallographic examination of a transverse cross section of the aluminum-alloy punchout fragment (Fig. 23) revealed that the punchout occurred with only a minimal tendency to shear in a direction normal to the plate. Instead, it sheared mostly at an angle in two stages. The microstructure near the sheared edges of the fragment (Fig. 24) revealed severe distortion of the grains along adiabatic shear bands. This effect is commonly observed in metal targets impacted by projectiles at high velocities. ${ }^{5}$ Examination of cross sections of the flyer plate taken transverse and parallel to the clad axis indicated that the plate was oriented with the rolling direction parallel to the axis of the fueled clad at impact (Fig. 25).

\section{Flyer Plate Test 3}

In the third test, the aluminum flyer plate collided with a heated $\left(1080 \pm 10^{\circ} \mathrm{C}\right)$ clad at $1173 \pm 60 \mathrm{~m} / \mathrm{s}$. Clad M-12 completely penetrated the plate, fragmenting it into about 20 pieces, but a single punchout was not recovered. Instead, we recovered aluminum fragments, identified as originating from the clad-penetrated area, which averaged less than $0.5 \mathrm{~g}$ each. The clad, shown in Fig. 26, was recovered at a sawdust depth of $1.37 \mathrm{~m}$. It exhibited a $0.4-\times 11-\mathrm{mm}$ transverse crack on the vent cup radius of the contact face. The breach area of the crack was $2.7 \mathrm{~mm}^{2}$. A blowout breach, with an area of $141 \mathrm{~mm}^{2}$, occurred in the vent end radius $180^{\circ}$ from the point of flyer plate impact. The total fuel release was $6.77 \mathrm{~g}$.

Metallographic examination of a transverse section of the impact face showed a thin layer of an iridium/aluminum intermetallic compound on the exterior surface (Fig. 27). The compound did not penetrate the iridium grain boundaries. The interior surface exhibited an undulating contour (Fig. 28), suggesting that the cladding conformed to fragments of the urania pellet. The exterior surface also exhibited surface ir- regularities (Fig. 29) in an area near the impact face center. Comparison of the microstructure at the center of the impact face (Fig. 28) with that at $90^{\circ}$ (Fig. 30) indicated that the grain shape was elongated at the center of the impact face. Because the contour of the iridium wall was irregular, we could not determine the reduction in thickness at the impact face center. The average grain size was 34 grains/thickness.

To identify the source of the fragment that caused the blowout breach on the back of the test article, we examined a cross section through the vent end that included the fracture edge where the fragment was believed to have entered the cladding. A gray intermetallic compound was present on the fracture surface as well as on the surfaces of small cracks on the exterior surface (Fig. 31). Electron microprobe (EMP) analysis of the compound indicated that the principal constituents were aluminum ( 70.9 at.\%) and iridium (28.0 at.\%). Figure 32 shows the area analyzed and the distribution of aluminum and iridium as revealed by $\mathrm{x}$-ray dot maps. Low levels of tungsten and copper (approximately 1.0 at.\%) were also detected, but these concentrations were insufficient to produce $\mathrm{x}$-ray dot maps. The results indicate that the fueled clad collided with a fragment of the 2024 aluminum-alloy flyer plate.

The 20 fragments of the flyer plate recovered from the catch tube ranged in weight from 0.13 to $82.96 \mathrm{~g}$. A fragment of the flyer plate (Fig. 33) identified as a portion of the punchout fragment was metallographically examined in both transverse and longitudinal cross sections. The orientation of the plate at impact, deduced from the fragment microstructures (Fig. 34), was with the rolling direction parallel to the fueled clad axis.

\section{Flyer Plate Test 4}

In FPT-4, the flyer plate thickness was significantly increased. A 38.1-mm-thick aluminum plate collided with the heated $\left(1050 \pm 10^{\circ} \mathrm{C}\right)$ clad at $271.3 \pm 7.6 \mathrm{~m} / \mathrm{s}$. The virgin clad, M-33, indented the plate to a depth of $4.95 \mathrm{~mm}$ (Fig. 35) and was fragmented into 11 pieces (Fig. 36), ranging in weight from 0.17 to $11.12 \mathrm{~g}$. We recovered $85 \%$ of the iridium at a sawdust depth of 1.0 to $1.5 \mathrm{~m}$. All of the simulant fuel was released.

We metallographically examined a cross section, taken transverse to the fueled clad axis, of a large iridium fragment (Fig. 37) identified as the impact face because it matched the cavity on the flyer plate. The aspolished cross section (Fig. 38) revealed numerous shallow cracks on the exterior surface and a continuous intermetallic coating that followed the surfaces of the cracks. A porous, nonmetallic material was present in the small pockets formed by the cracks. According to 
EMP analysis, the principal constituents of the coating were alumınum and iridium, and the nonmetallıc materal was composed principally of $\mathrm{UO}_{2}$ Smaller particles containıng varying concentrations of aluminum, uranium, indium, and oxygen were randomly mixed with the $\mathrm{UO}_{2}$ We believe that these small particles are remnants of polishing debris and abrasive embedded in the pores of the $\mathrm{UO}_{2} \mathrm{X}$-ray dot maps (Fig 39) show the distribution of elements in a typical area

The microstructure of the clad fragment edge (Fig 40) exhibited a ductıle fracture mode and the dark etching typically seen in indium that has expenenced plastic deformation below its recrystallization temperature The indium microstructure at the center of the impact face is illustrated in Fig 41 The indium grains are extensively elongated in the plane of the flattened capsule wall, with approximately a $25 \%$ reduction of thickness The effect of deformation on the grain shapes and the dark etchıng are clearly demonstrated in this photomicrograph The indium grain size was 36 grains/thickness

The flyer plate was spalled at about a $45^{\circ}$ angle on the lower charge side, but it was not fragmented as a result of collision with the clad A cross section of the cavity in the flyer plate ( $\left.\mathrm{F}_{1 \mathrm{~g}} 42\right)$ was metallographically examined The sample included the center of the cavity and one edge to the maximum depth of $495 \mathrm{~mm}$ Figure 43 shows the microstructure at the surface of the center of the impact area, and Fig 44 shows the bulk microstructure As expected, the near-surface grains are severely flattened compared with those of the undeformed region The aluminum-alloy microstructure near the edge of the impact area ( $\mathrm{F}_{1} \mathrm{~g} 45$ ) lllustrates the development of adiabatic shear bands and small fractures

\section{DISCUSSION}

Results of the flyer plate tests indicate a correlation between plate velocity and fueled clad breach area An increase in plate velocity appears to increase the breach area of the fueled clad However, the fuel release directly resulting from collision of the fueled clad with the 353 $\mathrm{mm}$ plate remained less than $05 \mathrm{~g}$ The larger, blowouttype breach ( $180^{\circ}$ to the FPT-3 clad impact face), which caused most of the $677 \mathrm{~g}$ fuel release, apparently resulted from a secondary collision with an aluminum fragment in the catch medium

Impact of the fueled clad by a $381-\mathrm{mm}$-thick aluminum flyer plate at about $270 \mathrm{~m} / \mathrm{s}$ resulted in fragmentation of the fueled clad and a complete loss of fuel X-ray images showed the flyer plate in FPT-4 leaning forward slightly This inclined position probably caused the plate to initially contact the clad at the vent cup radius (top) The fueled clad indentation on the flyer plate is slightly deeper in the upper portion Apparently this initial contact resulted in an immediate release of fuel into the space between the flyer plate and the lower part of the fueled clad Small amounts of the $\mathrm{UO}_{2}$ were trapped in the U-shaped surface cracks that formed as the clad was elongated by the impact and as grain boundaries were penetrated by the iridium/alumınum intermetallic compound

At lower impact velocities, fueled clad breach location may have been affected by the orientation of the flyer plate rolling direction with respect to the fueled clad major axis In FPT-1 and FPT-2, the major cracks observed on the fueled clads were parallel to the rolling direction of the flyer plates This situation is completely opposite in FPT-3 in which the rolling direction of the plate was perpendicular to the resultant crack on the fueled clad However, not enough data are avallable to positively determine such a correlation

The temperature of the fueled clads at impact in the first two tests (estımated at $1025^{\circ} \mathrm{C}$ ) was lower than the intended $1091^{\circ} \mathrm{C}$ However, this temperature difference does not appear to have adversely affected the response of the iridium clad

The very fine grained microstructures (33 grains/thickness, average) of the iridium clads used in the tests are probably not representative of flight components at the tıme of launch RTG testıng after assembly may involve approxımately $200 \mathrm{~h}$ at operatıng temperatures that would probably yield a grain size of about 23 grains/thickness ${ }^{6}$ Although the increased grain size would alter the indium response somewhat, the fuel release would not be significantly different, because the breach location and the extent of deformation are determined primarily by the behavior of the edges of the flyer-plate punchout and by the fuel pellet

\section{v. CONCLUSIONS}

On the basis of the test results described above, we can conclude the following about the response of the GPHS fueled clads to flat-on collision by space shuttle alloy flyer-plate-type fragments

1 Flat-on collisions of $353-\mathrm{mm}$-thick space shuttle alloy plate-type fragments with $\mathrm{UO}_{2}$-fueled Iridium clads (previously exposed to an estımated $345 \mathrm{MPa}$ overpressure) at velocities up to 1170 $\mathrm{m} / \mathrm{s}$ result in minor fueled clad breaching

2 Flat-on collision of a 381 -mm-thıck space shuttle alloy flyer-plate-type fragment with a $\mathrm{UO}_{2}$-fueled inidium clad at a velocity of $270 \mathrm{~m} / \mathrm{s}$ results in a total release of fuel 


\section{RECOMMENDATIONS}

The flyer plate tests completed to date have demonstrated that flat-on impacts of GPHS fueled clads by 3.53-mm-thick flyer-plate-type fragments at velocities from about 350 to $1200 \mathrm{~m} / \mathrm{s}$ result in minor fueled clad breaching. However, the fueled clad damage and resultant fuel release appear to increase with plate thickness. Additional tests are needed to determine the maximum flyer plate velocity at which the clads do not breach. Also, the result of a flyer plate collision with the fueled clad oriented end-on could prove important in the safety analysis. Accordingly, we recommend conducting additional tests to determine

(1) the minimum velocity of a $3.53-\mathrm{mm}$-thick flyer plate required to breach the fueled clad, and

(2) the effect of flyer plate collision with fueled clads oriented end-on.

\section{ACKNOWLEDGMENTS}

We thank the following people for their valuable assistance in completing these tests: L. Berg, R. Bohannon, and other SNLA personnel for test range operations, flash $\mathrm{x}$-ray support, and velocity calculations; A. Herrera, M. Anstey, W. Hults, T. George, and J. Archuleta for test assembly and posttest recovery operations; D. Garinger for particle size analyses; C. Baca, D. Court, and F. Martinez for component design and assembly support; and W. B. Hutchinson for EMP analyses.

\section{REFERENCES}

1. A. B. Willoughby, C. Wilton, and J. Mansfield, "Liquid Propellant Explosive Hazards," URS Corporation document AFRPL-TR-68-92 (December 1968).

2. "GPHS Safety Verification Test Series Procedures Manual," Los Alamos National Laboratory document MST-5-83-19 (April 14, 1983).

3. "Space Shuttle Data for Planetary Mission Radioisotope Thermoelectric Generator (RTG) Safety Analysis," National Aeronautics and Space Administration report JSC 08116 (February 1985).

4. T. A. Cull, T. G. George, and D. Pavone, "GeneralPurpose Heat Source Development: Safety Verification Test Program Explosion Overpressure Test Series," Los Alamos National Laboratory report LA-10697-MS (in preparation).

5. H. C. Rogers, "Adiabatic Shearing-General Nature and Material Aspects," in Proceedings of 29th Sagamore Army Materials Research Conference Committee, Material Behavior Under High Stress and Ultrahigh Loading, Ed. by J. Mescall and V. Weiss (Plenum Press, New York, 1983).

6. D. Pavone, T. G. George, and C. E. Frantz, "GeneralPurpose Heat Source Safety Verification Test Series: SVT-1 Through SVT-6," Los Alamos National Laboratory report LA-10353-MS (June 1985). 

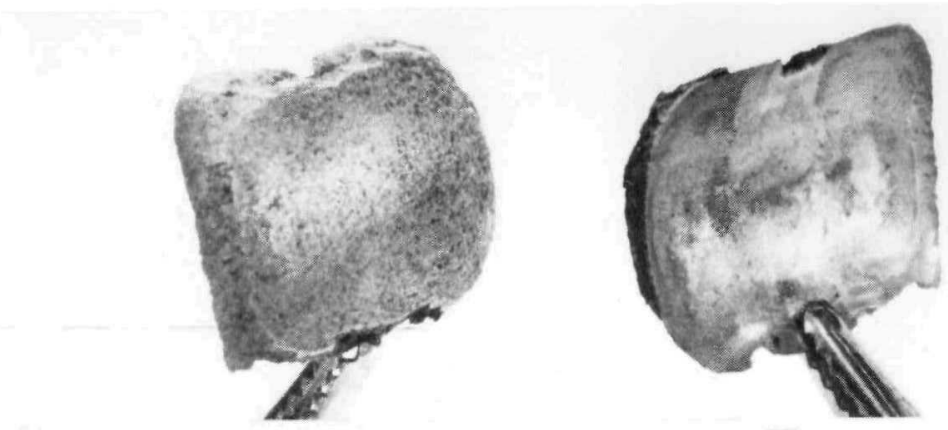

\section{Punched Aluminum Fragment}

(a)
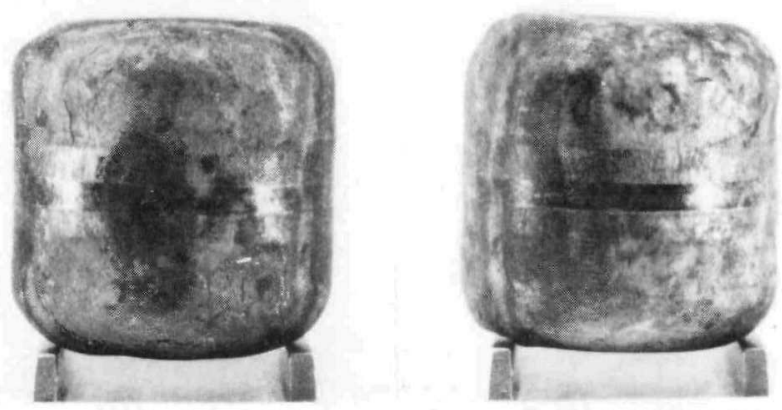

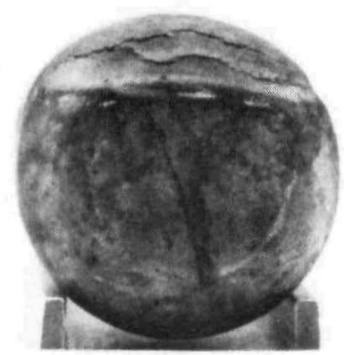

Pellet $\mathrm{M}-10$

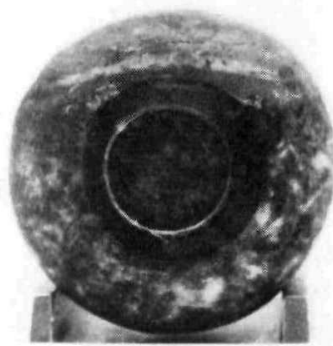

(b)

Fig. 5. (a) A punchout fragment was produced from the plate; (b) fueled clad M-10 (impact face, $90^{\circ}$, shield end, vent end) was impacted by a $3.53-\mathrm{mm}$-thick flyer plate at a velocity of $348.7 \mathrm{~m} / \mathrm{s}$ in FPT-1.

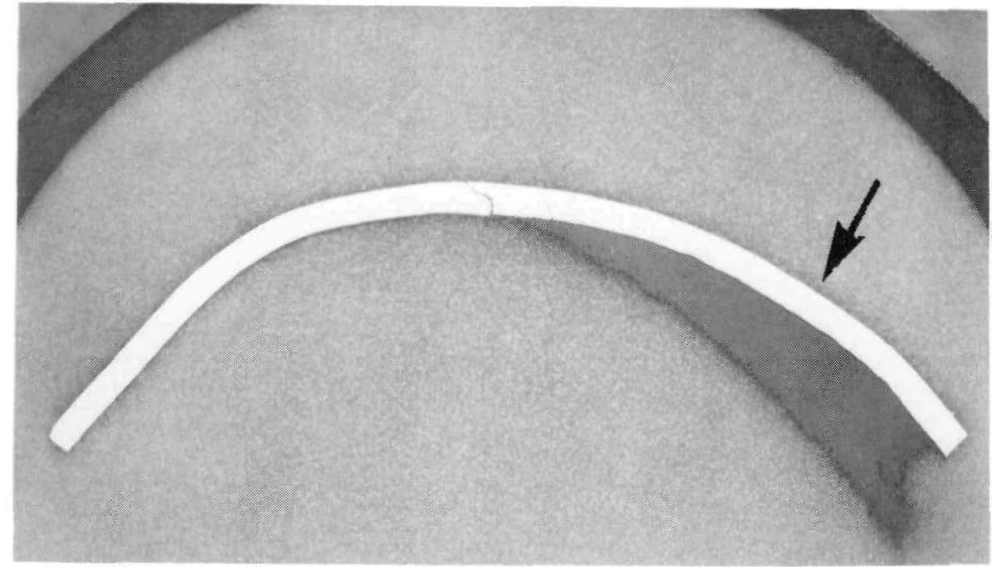

Fig. 6. An axial crack occurred in the wall of the M-10 vent cup. The arrow indicates the impact face center; as polished, $4 \mathrm{X}$. 


$$
\equiv
$$




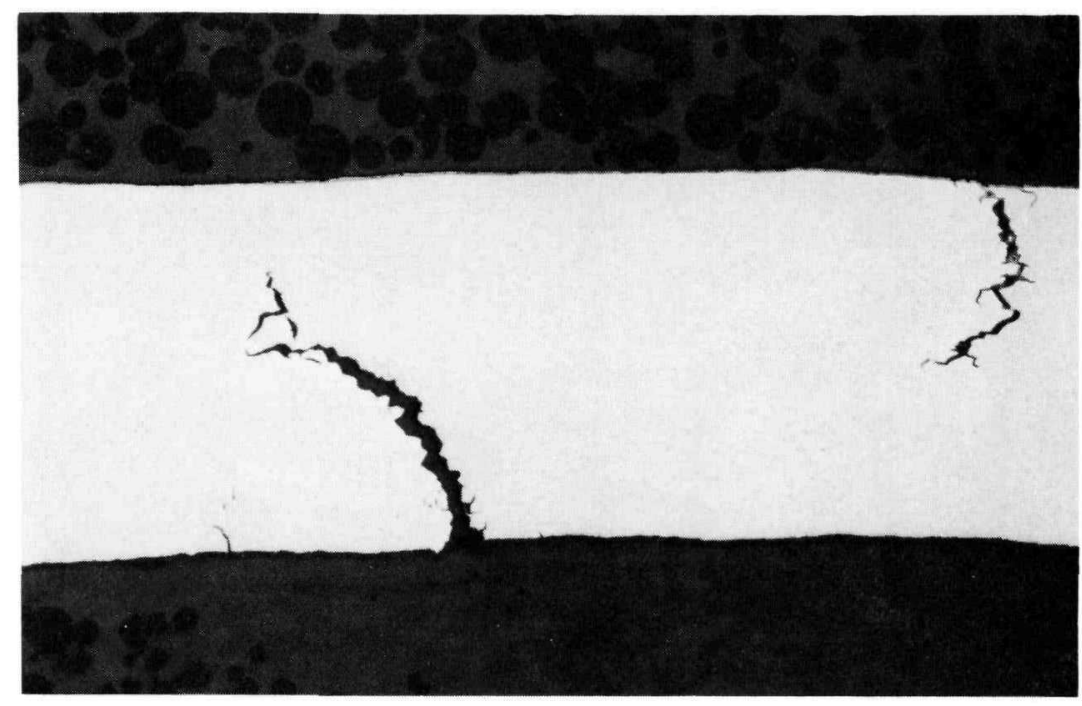

(a)

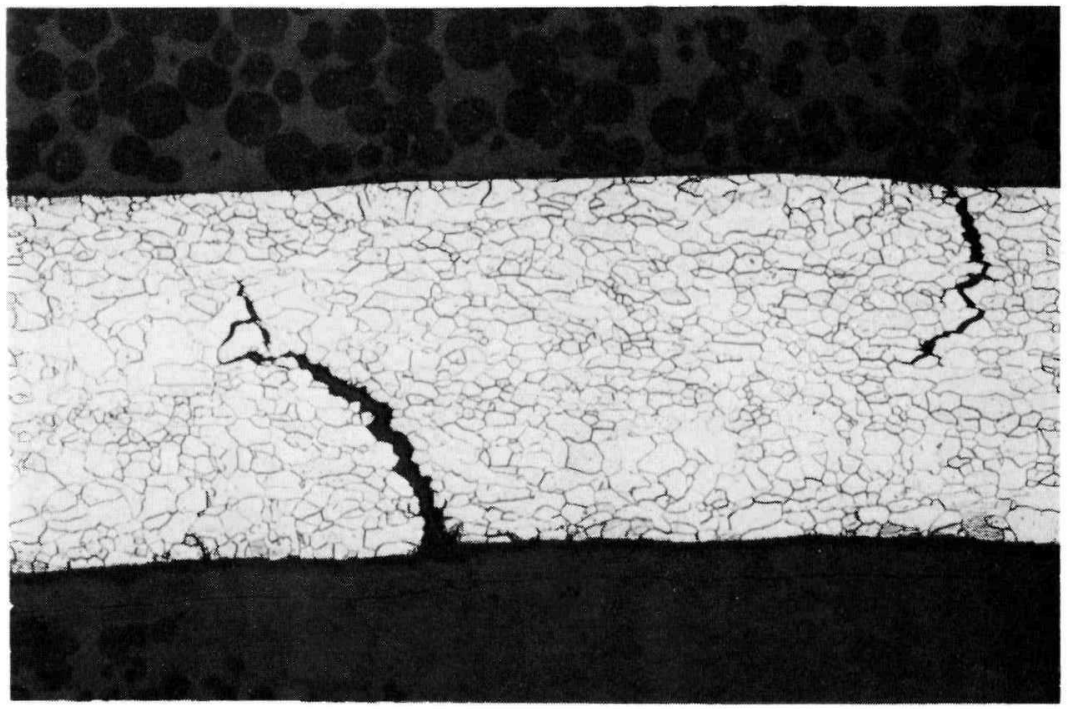

(b)

Fig. 8. Two nonpenetrating, intergranular cracks were observed near the $M-10$ axial breach; (a) as polished and (b) etched, both 50X. 


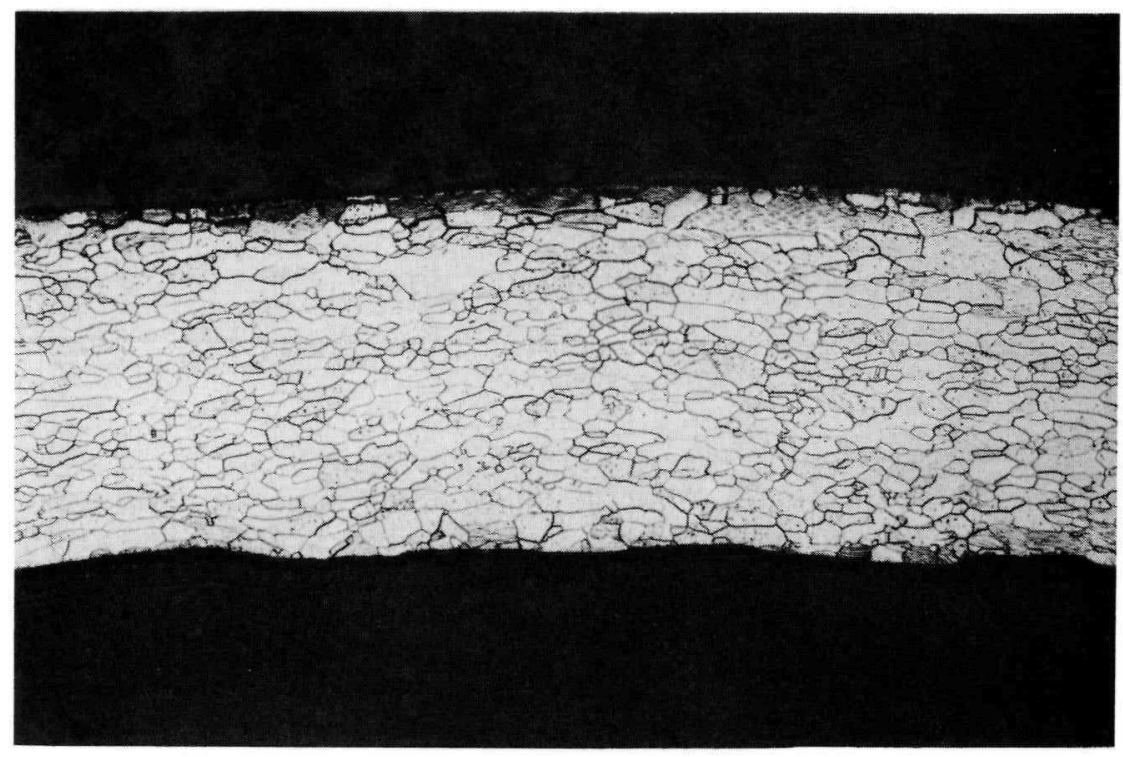

Fig. 9. The center of the M-10 impact face showed no significant distortion of the grains; etched, 50X.

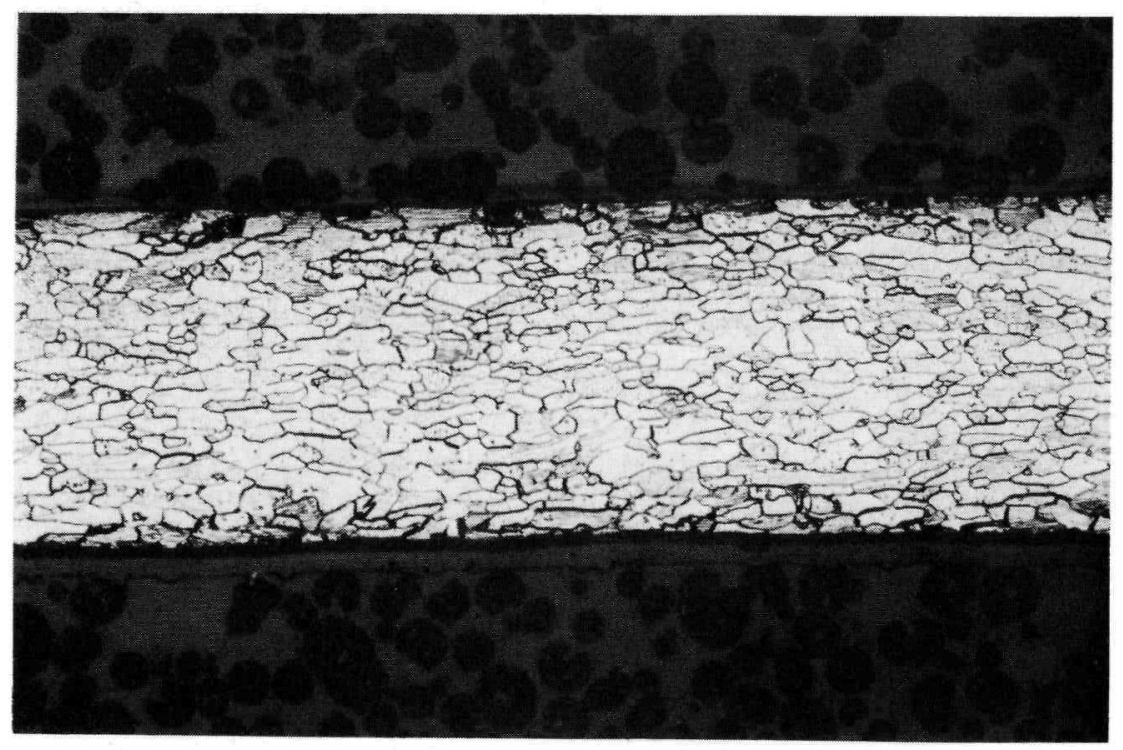

Fig. 10. M-10 microstructure at $90^{\circ}$ to the impact face center; etched, $50 \mathrm{X}$. 


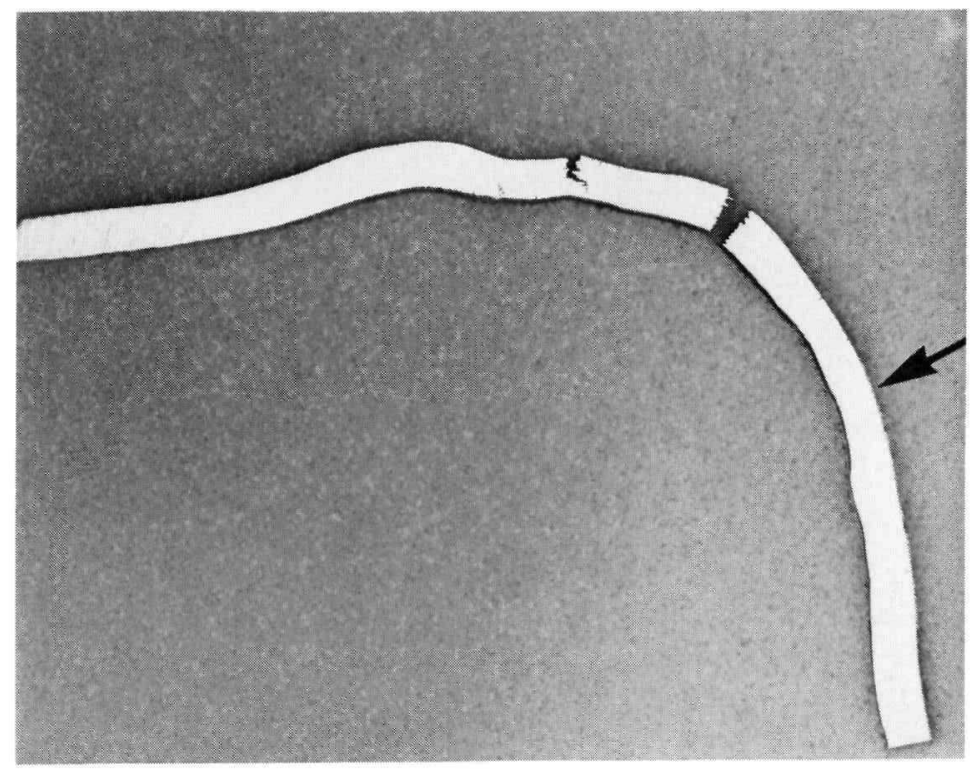

Fig. 11. An axial cross section through the crack at the end of the M-10 vent cup was metallographically examined. The arrow indicates the impact face center; as polished, $6.5 \mathrm{X}$.

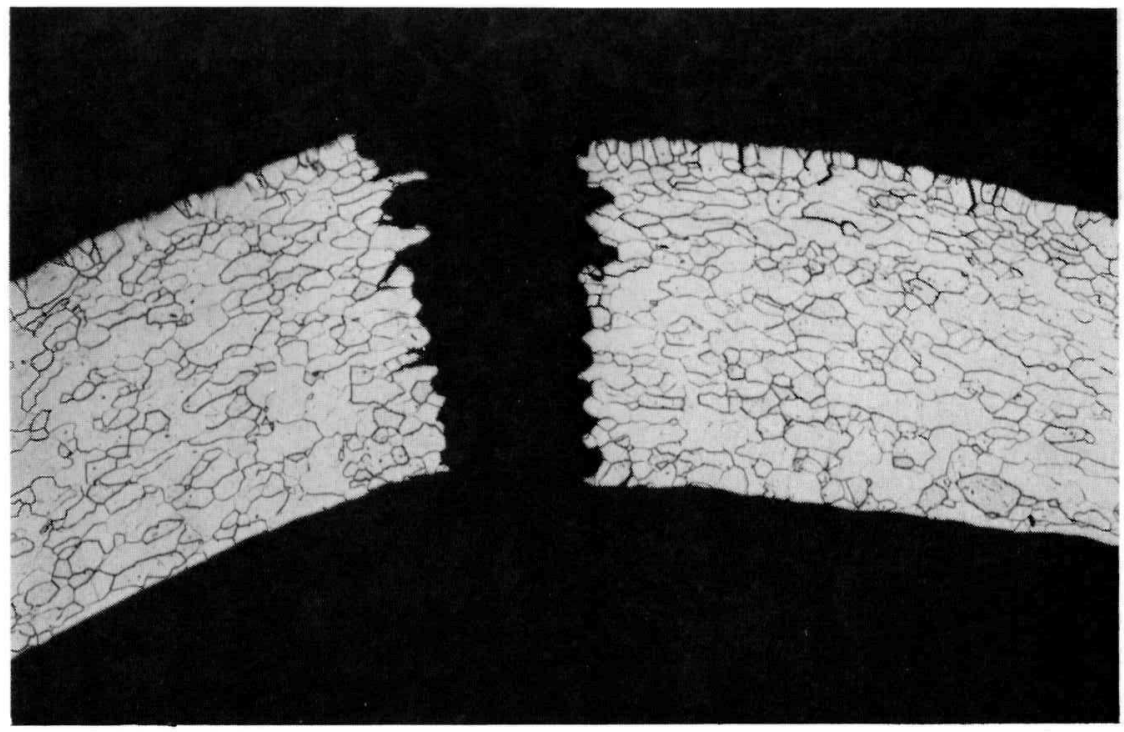

Fig. 12. A transverse crack on the M-10 vent end completely penetrated the iridium wall and was intergranular; etched, $50 \mathrm{X}$. 


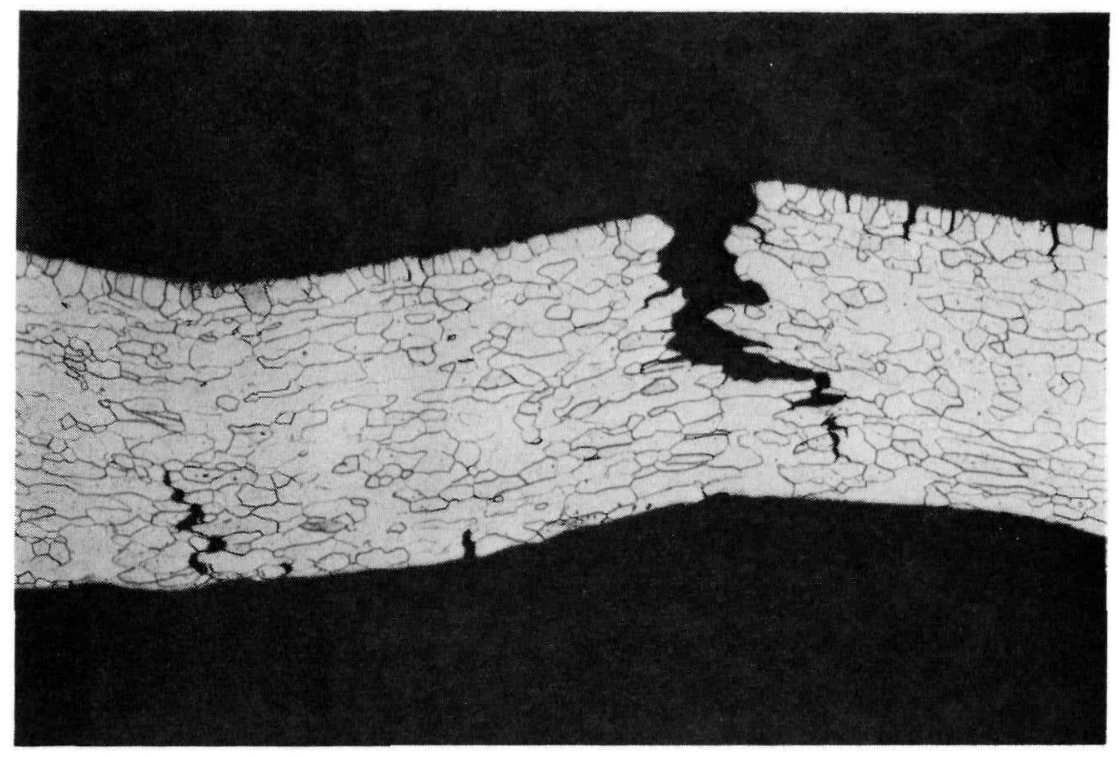

Fig. 13. An intergranular crack originated on the M-10 external surface and penetrated $85 \%$ of the wall thickness; etched, $50 \mathrm{X}$.

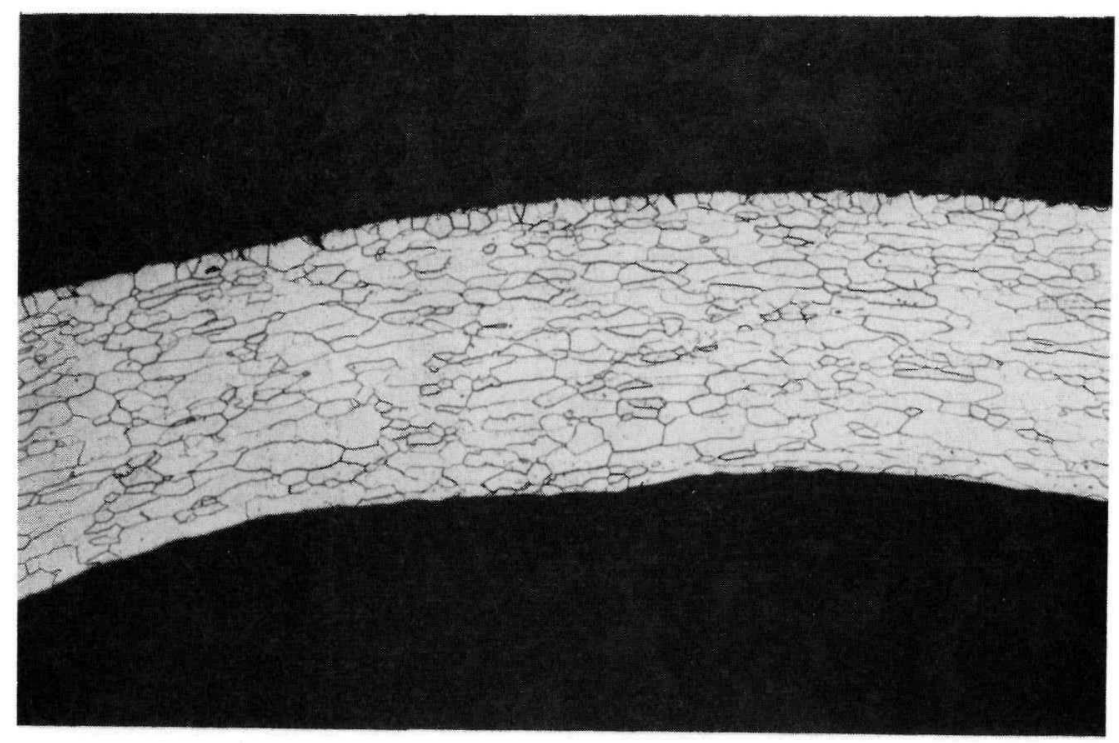

Fig. 14. Slight grain elongation was observed on the M-10 impact face; etched, 50X. 


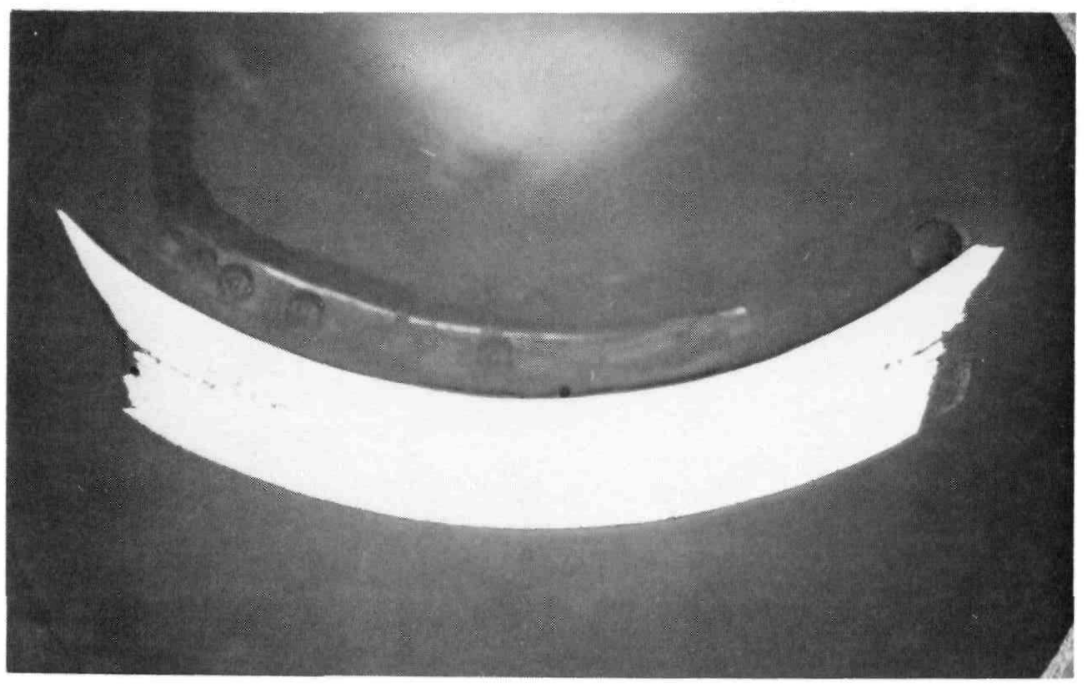

Fig. 15. The plate in FPT-1 sheared in a direction normal to the plane of the plate for about half of the plate thickness while the remainder sheared at a small angle to this plane; as polished, $4 \mathrm{X}$.

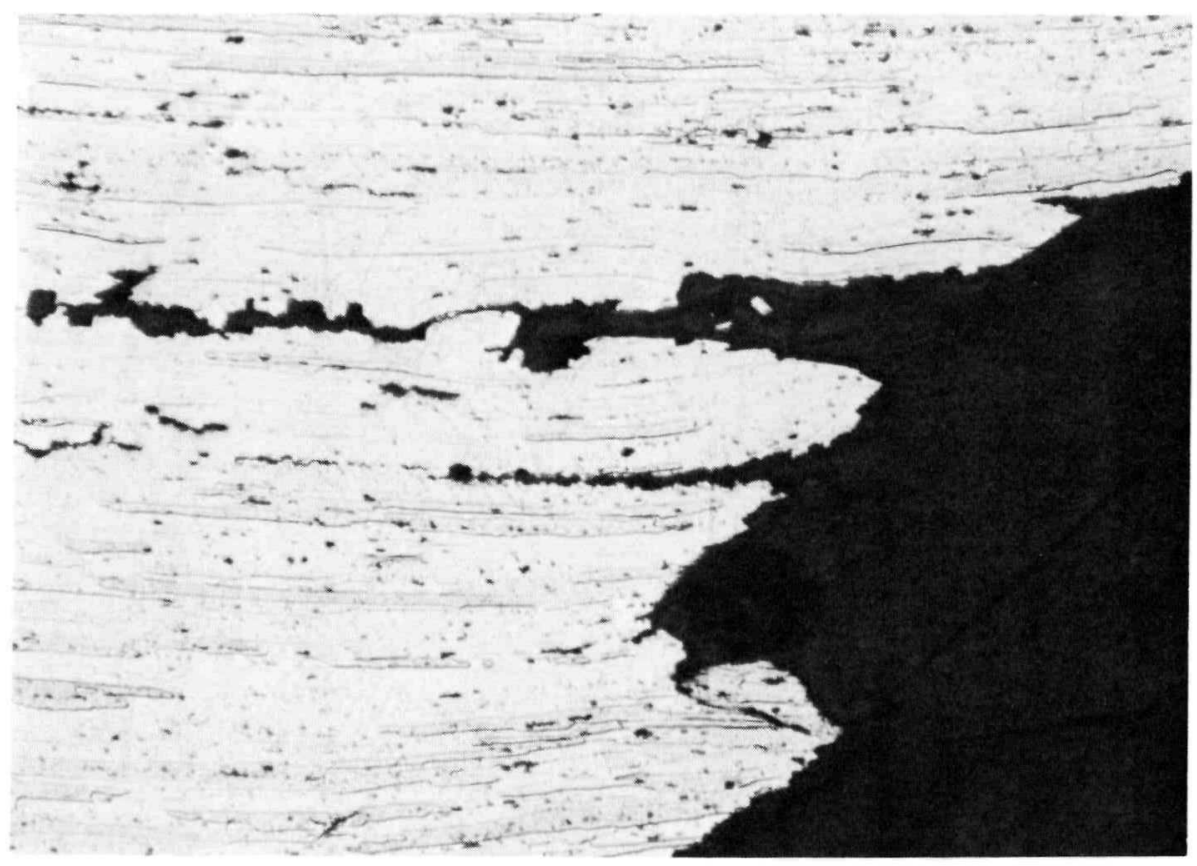

Fig. 16. An edge of the FPT-1 flyer plate near the centerline was metallographically examined; etched, $50 \mathrm{X}$. 


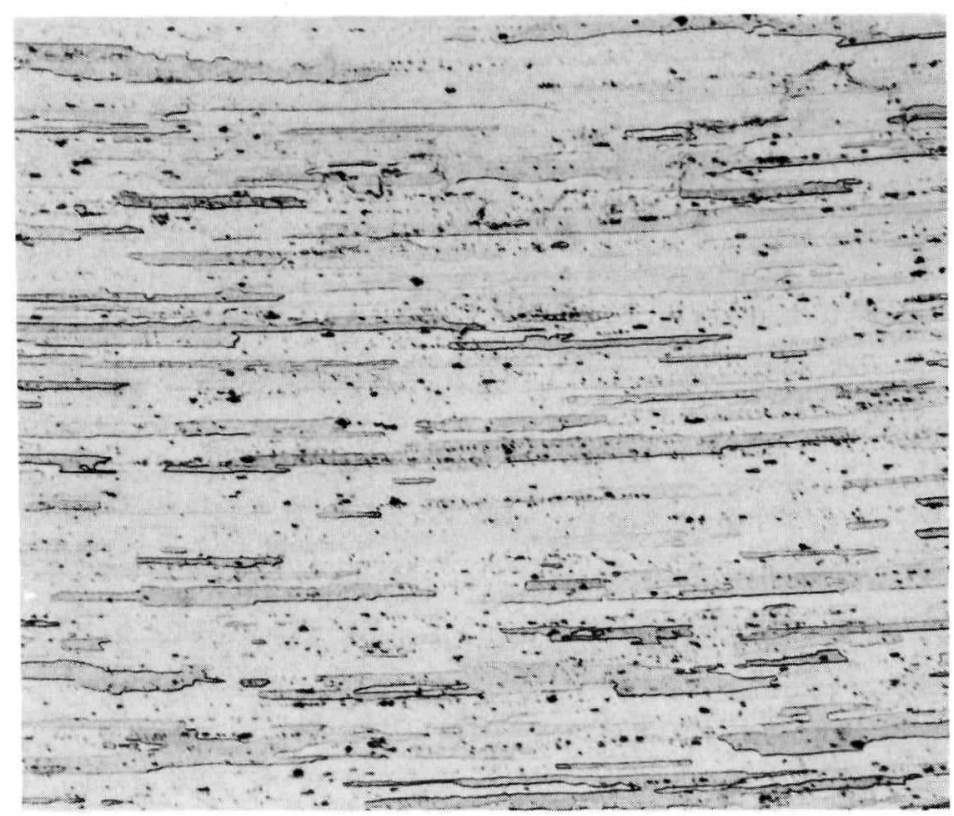

(a)

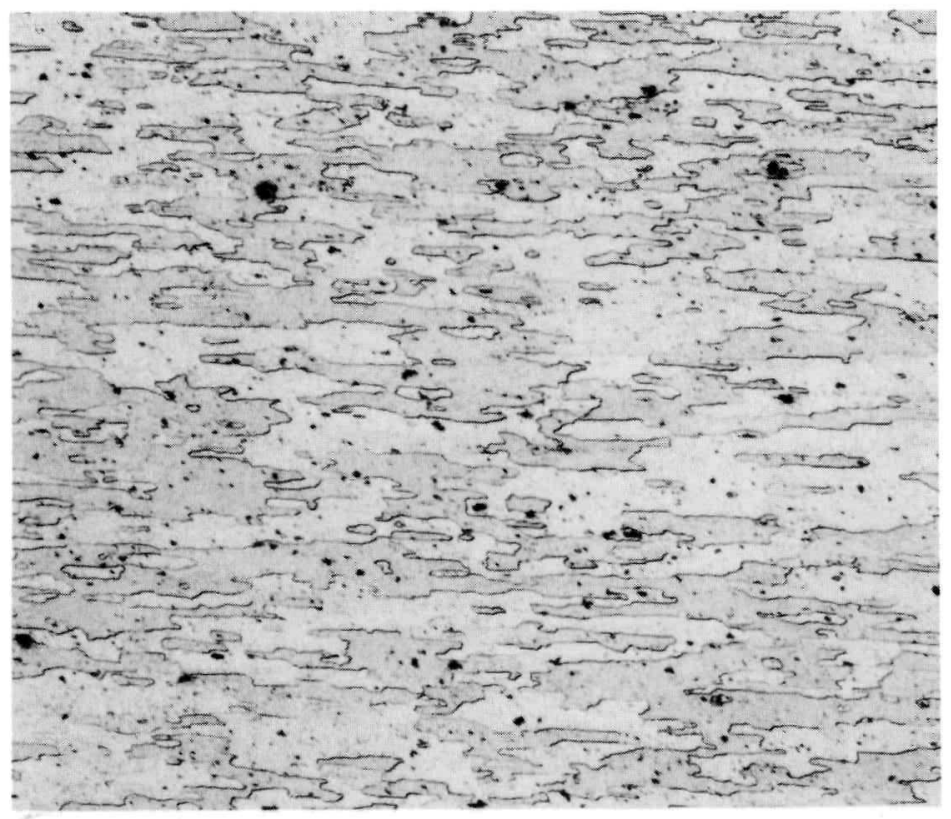

(b)

Fig. 17. Samples taken from the edge of the FPT-1 flyer plate indicate a rolling direction perpendicular to the M-10 axis at impact. (a) Transverse and (b) parallel; both etched, 50X. 

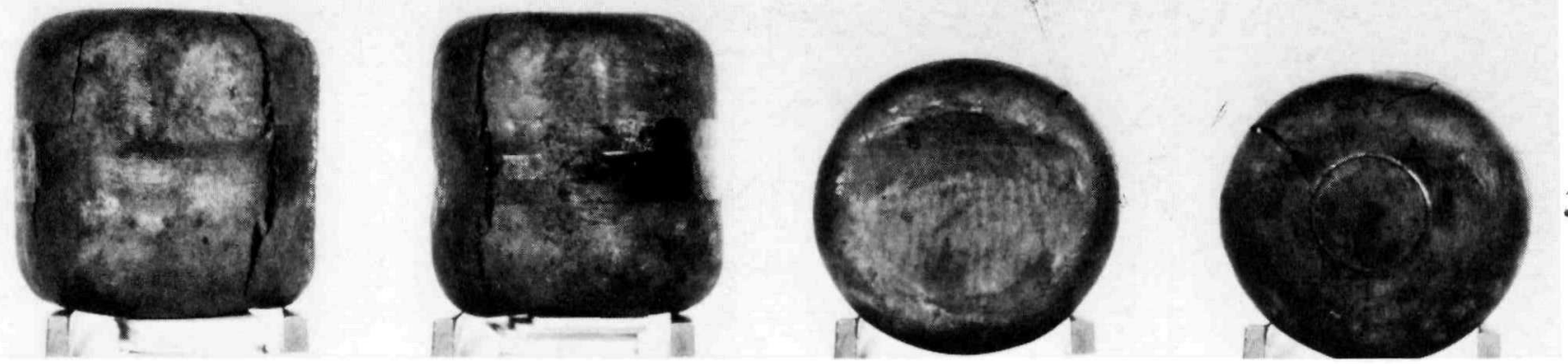

\section{Pellet $\mathrm{M}-9$}

(a)

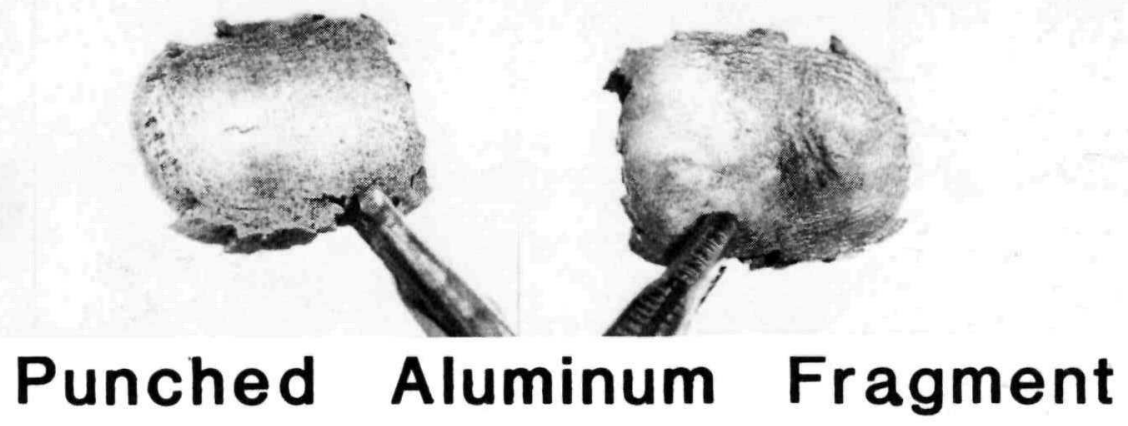

(b)

Fig. 18. (a) Fueled clad M-9 (impact face, $90^{\circ}$, shield cup end, vent end) was impacted by a 3.53-mm-thick aluminum flyer plate at a velocity of $623.9 \mathrm{~m} / \mathrm{s}$ in FPT-2; (b) a punchout fragment was produced from the plate.

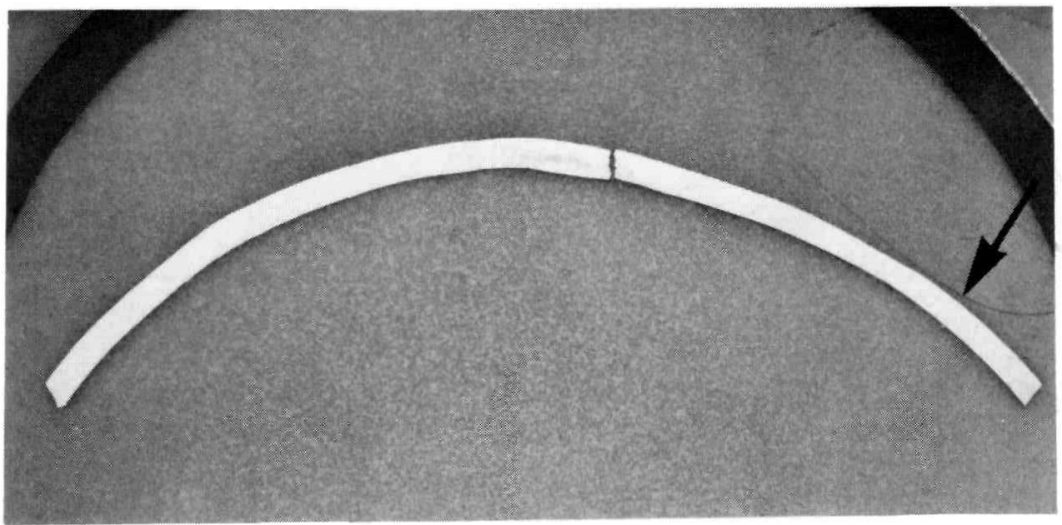

Fig. 19. An axial crack occurred in the wall of the M-9 vent cup. The arrow indicates the impact face center; as polished $4 \mathrm{X}$. 


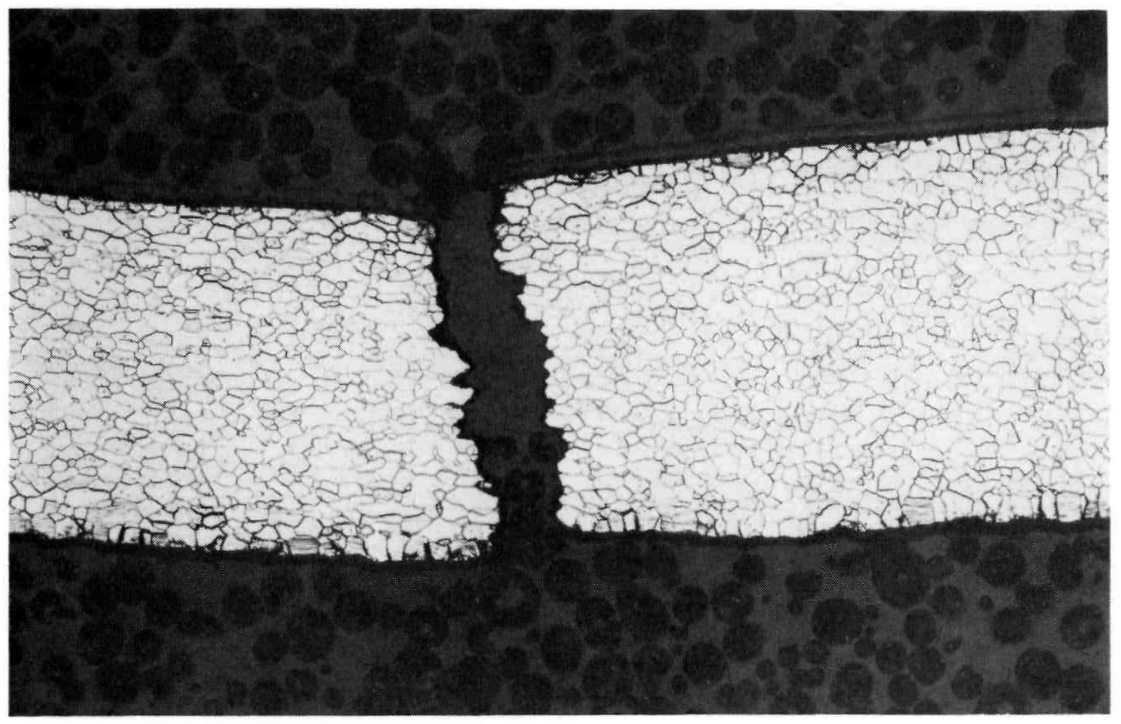

Fig. 20. The axial crack completely penetrated the M-9 iridium wall and was intergranular; etched, $50 \mathrm{X}$.

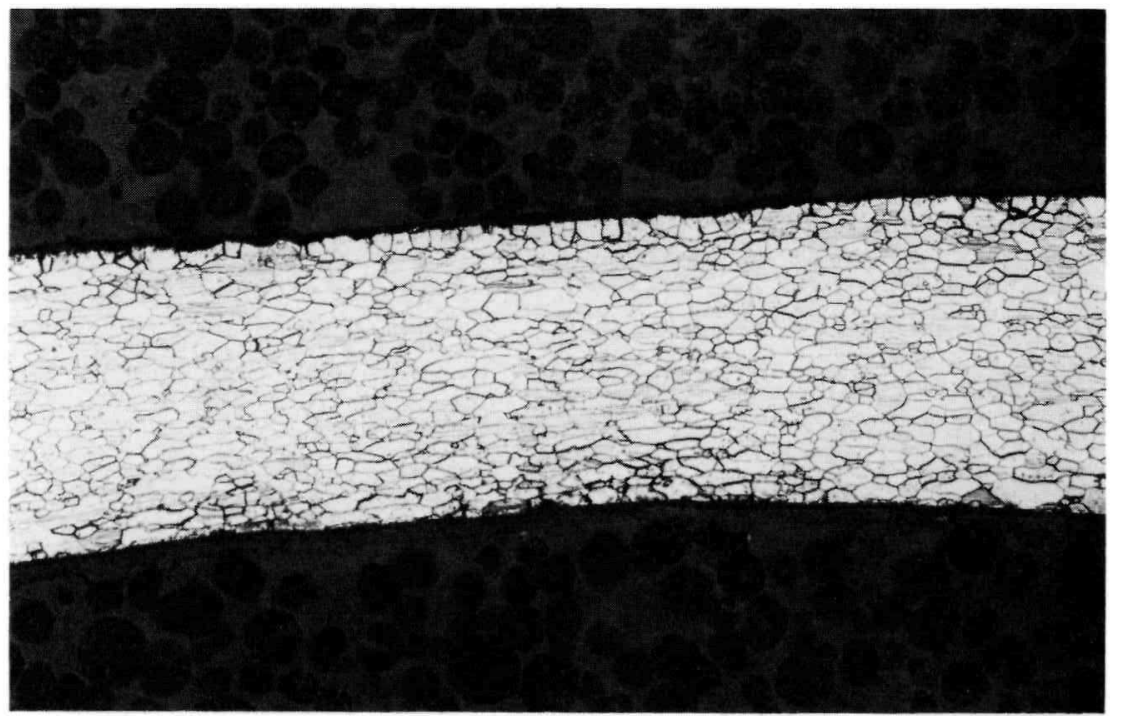

Fig. 21. The center of the M-9 impact face showed some grain elongation and a $17 \%$ reduction in thickness; etched, 50X. 


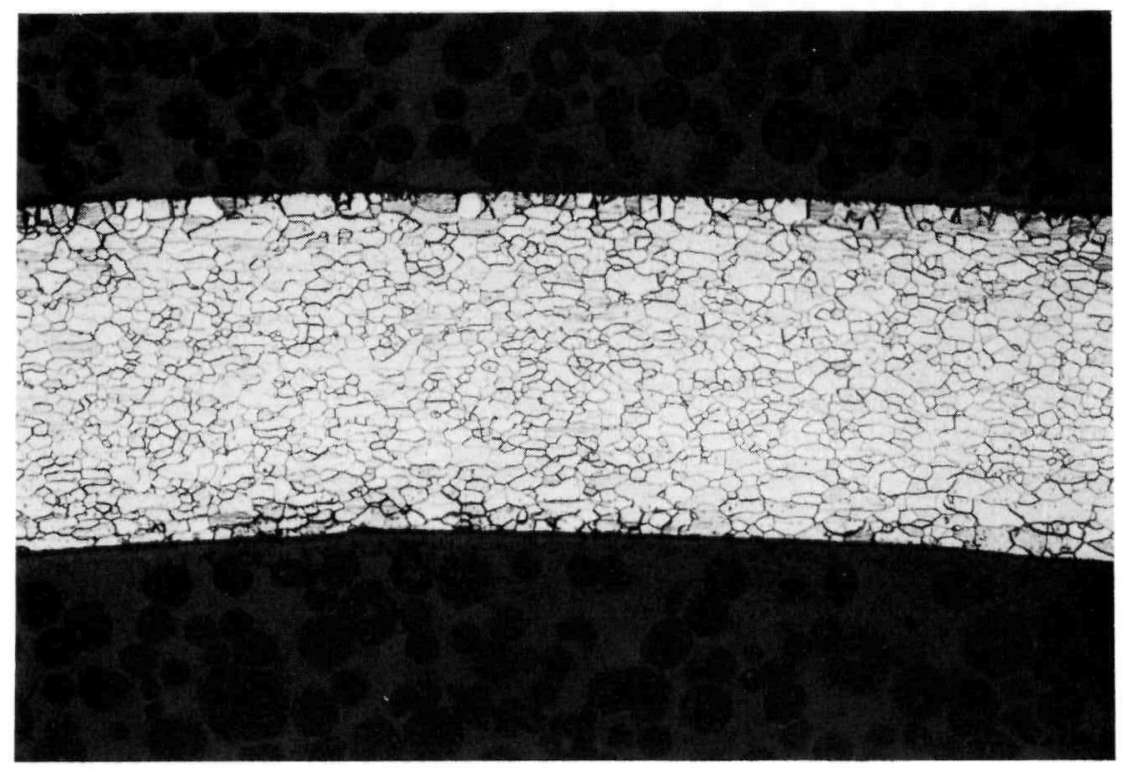

Fig. 22. M-9 microstructure at $90^{\circ}$ to the impact face center; etched, $50 \mathrm{X}$.

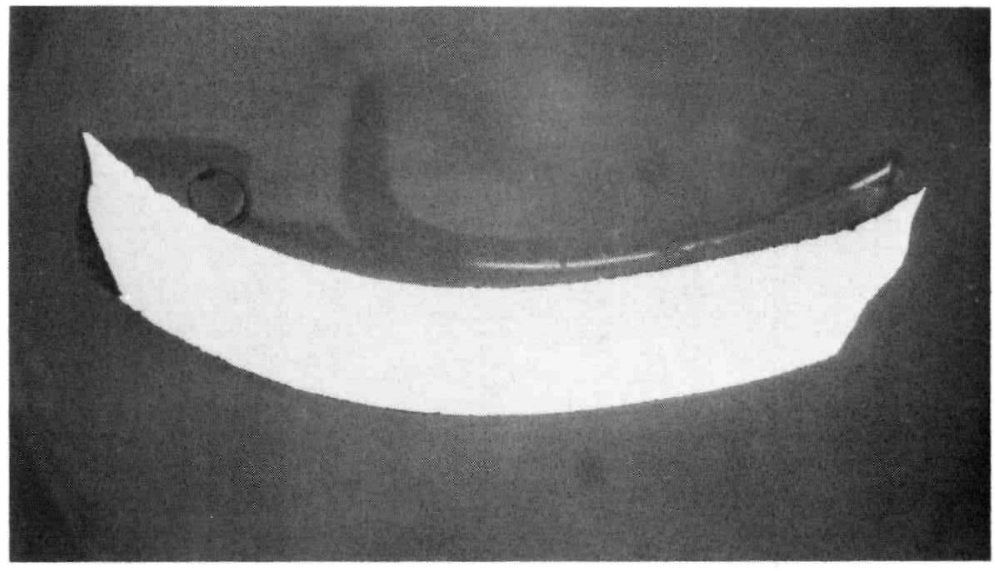

Fig. 23. The FPT-2 flyer plate punchout sheared at an angle in two stages; as polished, $4 \mathrm{X}$. 


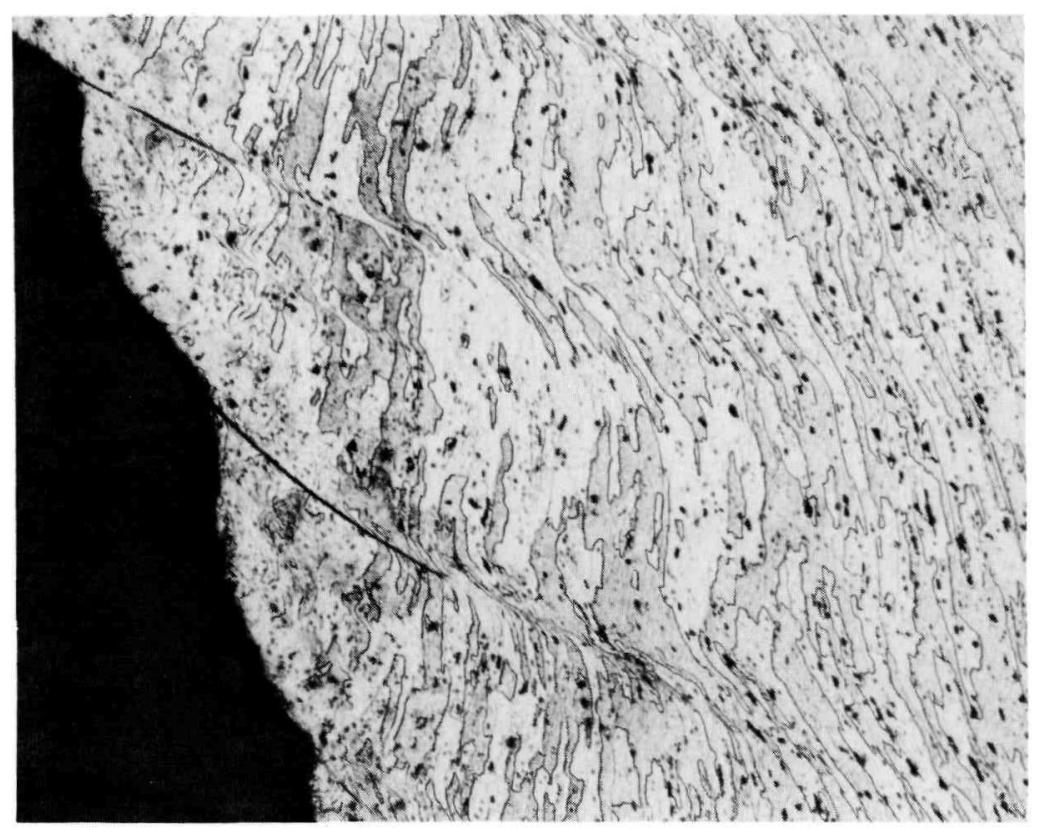

(a)

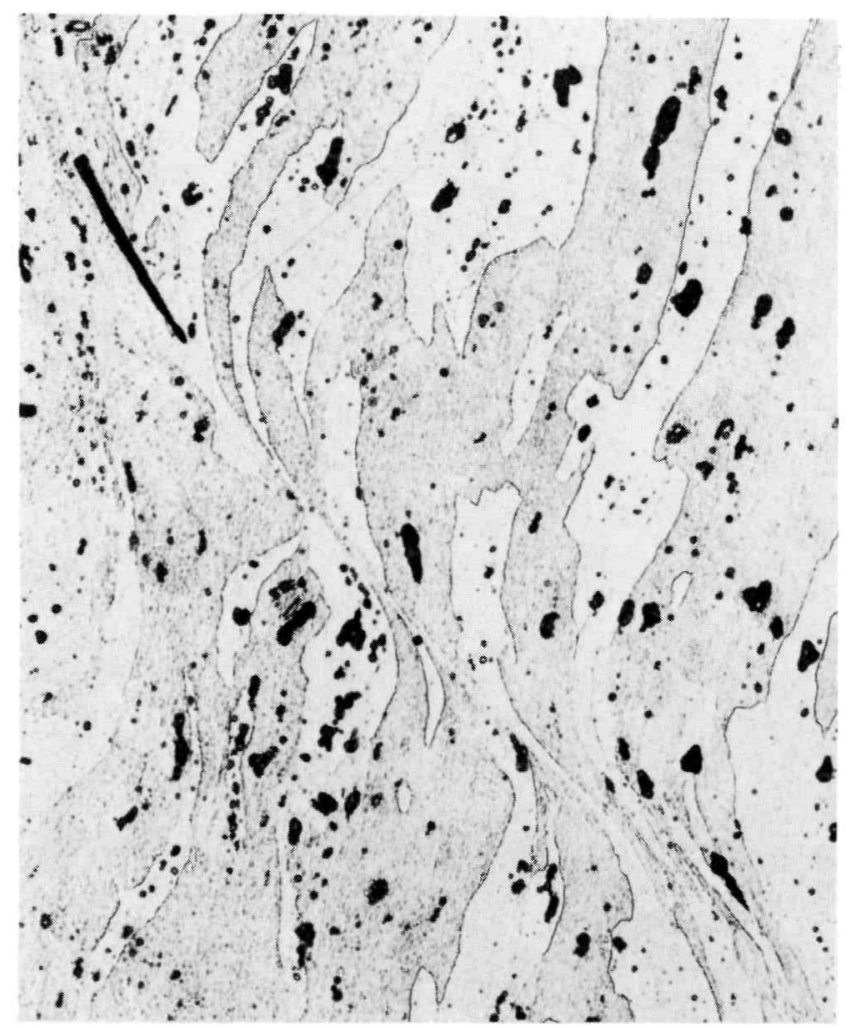

(b)

Fig. 24. The grains were severely distorted along adiabatic shear bands present at the edges of the FPT-1 punchout; (a) etched, 50X, and (b) etched, 200X. 


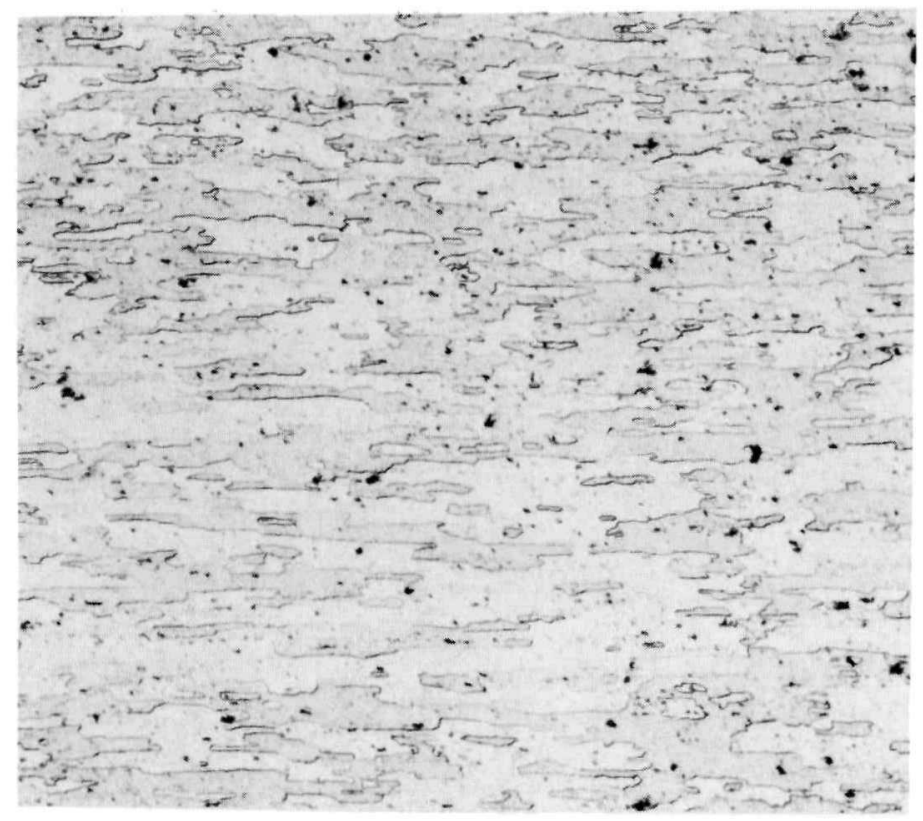

(a)

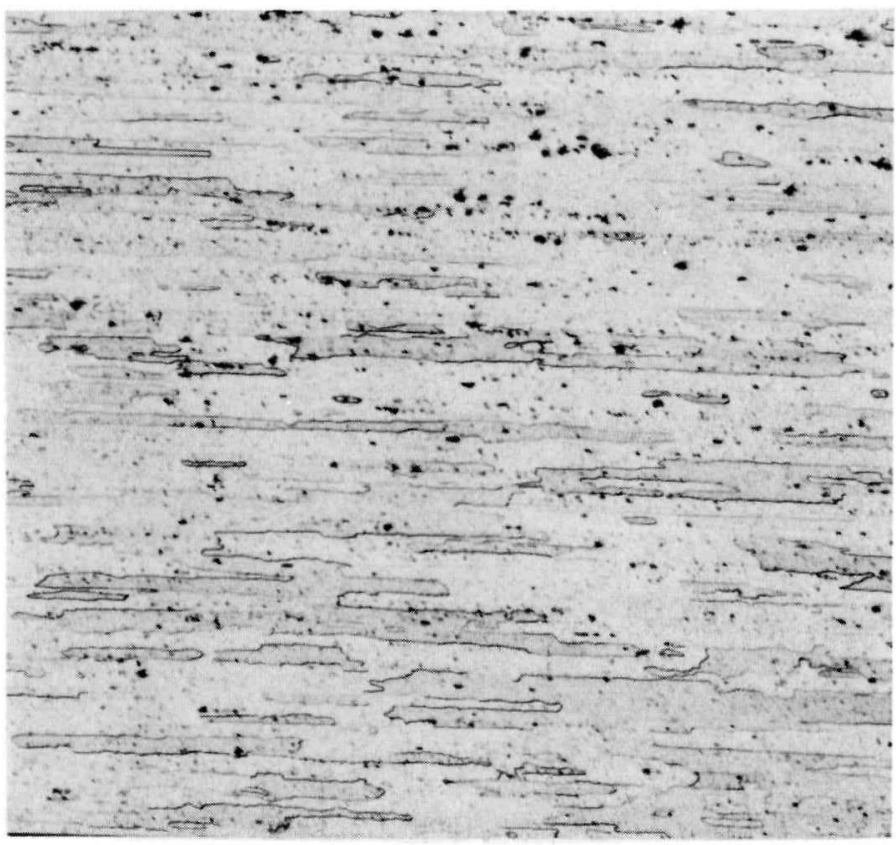

(b)

Fig. 25. Samples taken at the edge of the FPT-2 flyer plate indicate that the rolling direction of the plate was parallel to the M-9 axis at impact; (a) transverse and (b) parallel, both etched, 50X. 

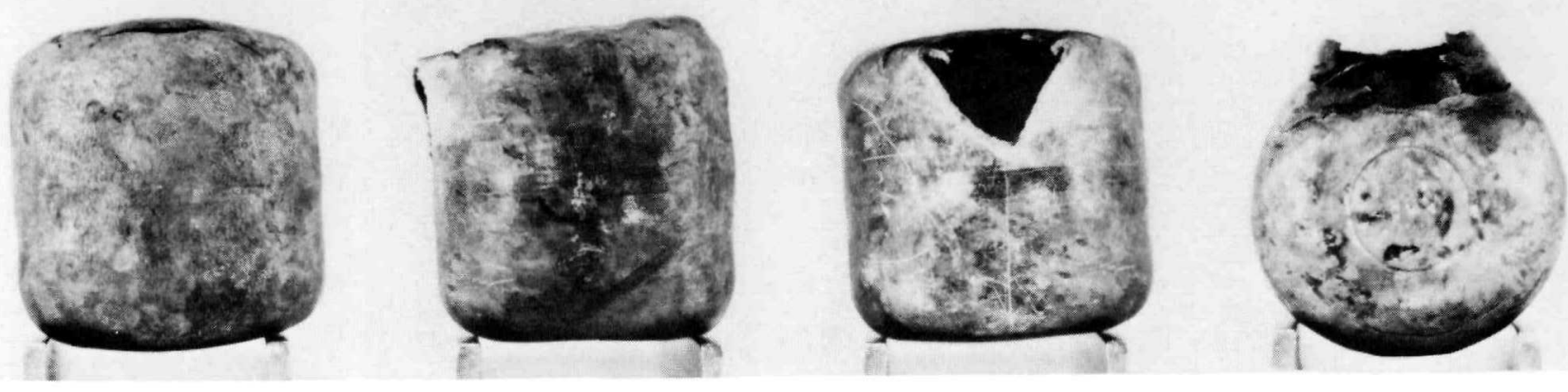

Fig. 26. Fueled clad M-12 (impact face, $90^{\circ}$, shield end, vent end) was struck by a 3.53-mm-thick flyer plate at a velocity of 1173 $\mathrm{m} / \mathrm{s}$ in FPT-3.

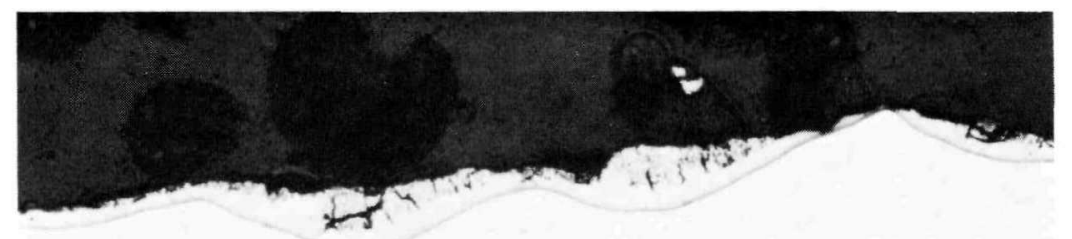

Fig. 27. A thin layer of an iridium/aluminum intermetallic compound was present on the M-12 impact face; as polished, $200 \mathrm{X}$.

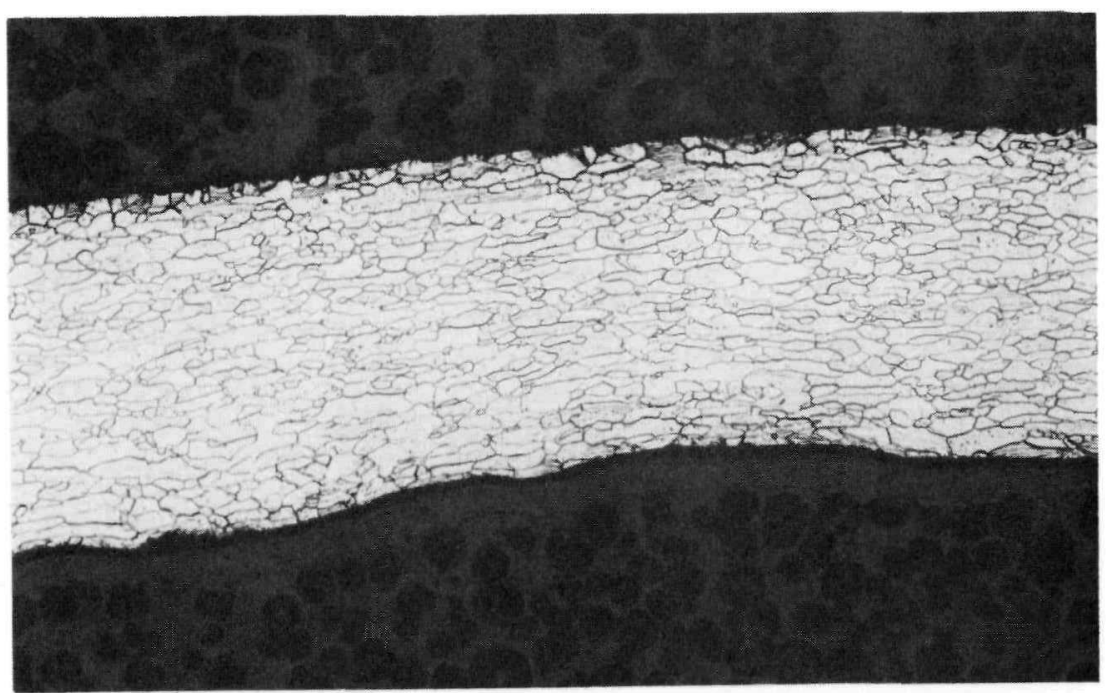

Fig. 28. The interior surface of the M-12 impact face exhibited an undulating contour; etched, 50X. 


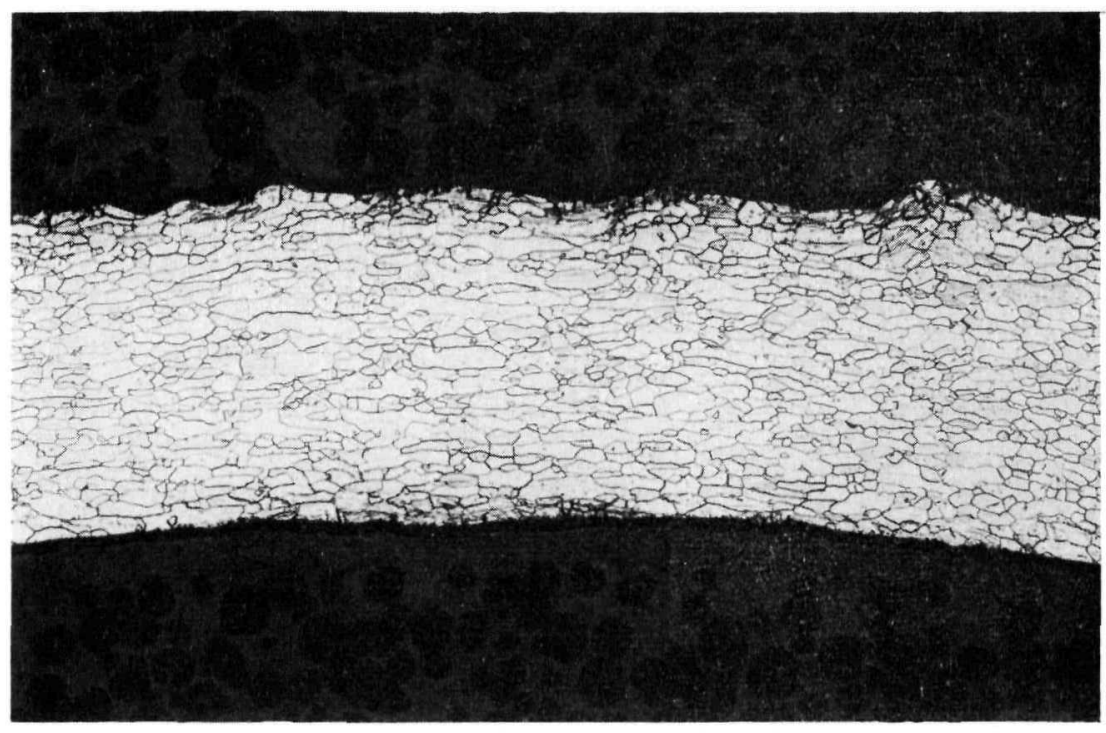

Fig. 29. The M-12 exterior surface exhibited surface contour irregularities near the center of the impact face; etched, $50 \mathrm{X}$.

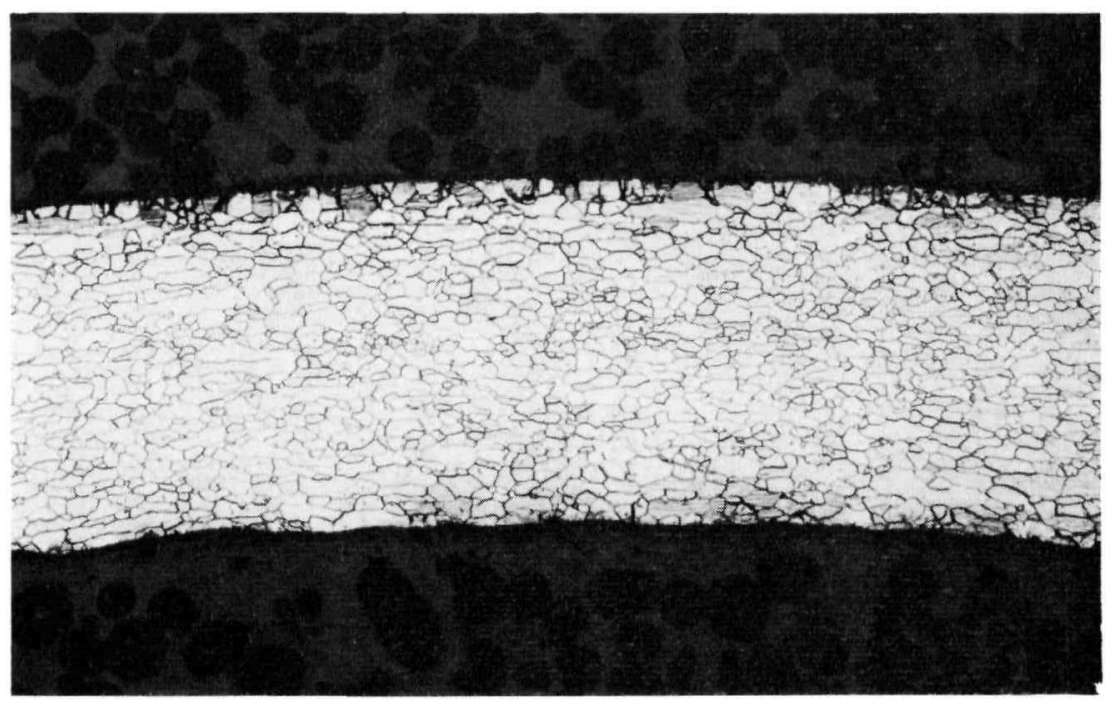

Fig. 30. M-12 microstructure at $90^{\circ}$ to the impact face center; etched, $50 \mathrm{X}$. 


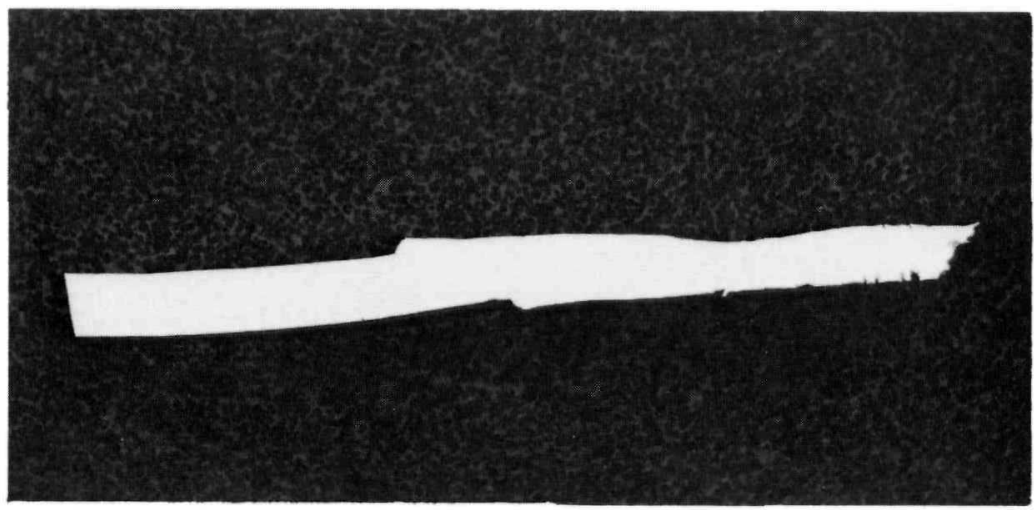

(a)

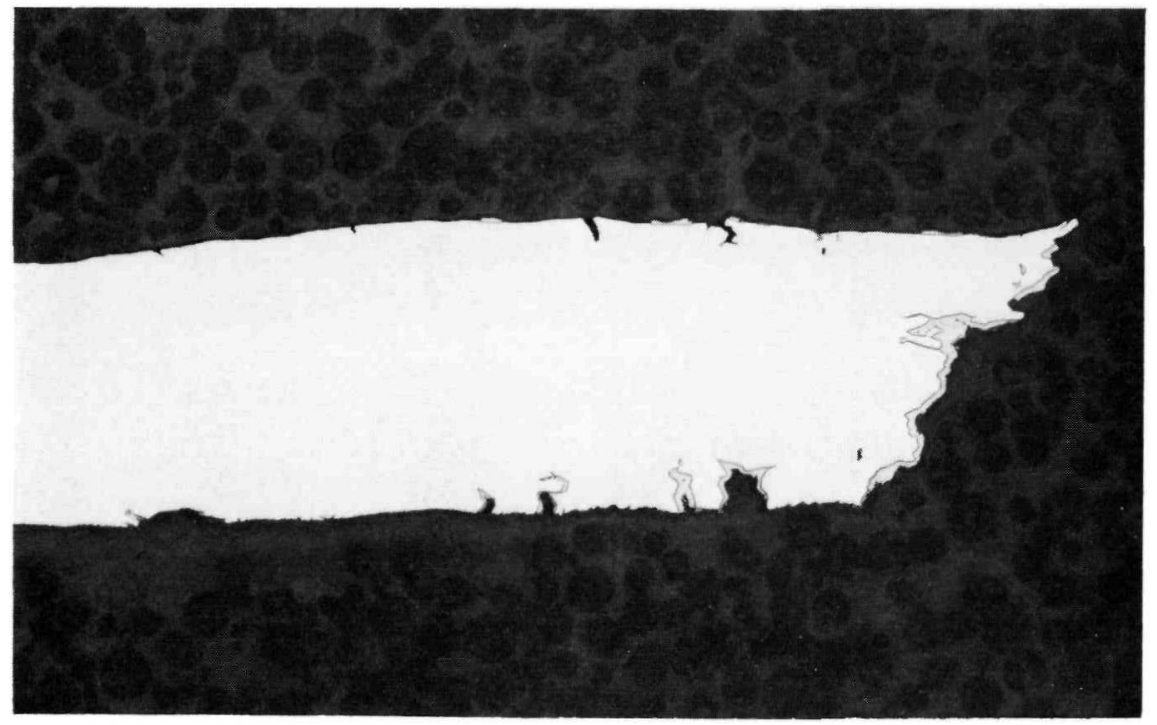

(b)

Fig. 31. A section of the M-12 vent end that included the edge of the blowout breach had an intermetallic compound deposited on the fracture surface; (a) as polished, 10X, and (b) as polished, 50X. 

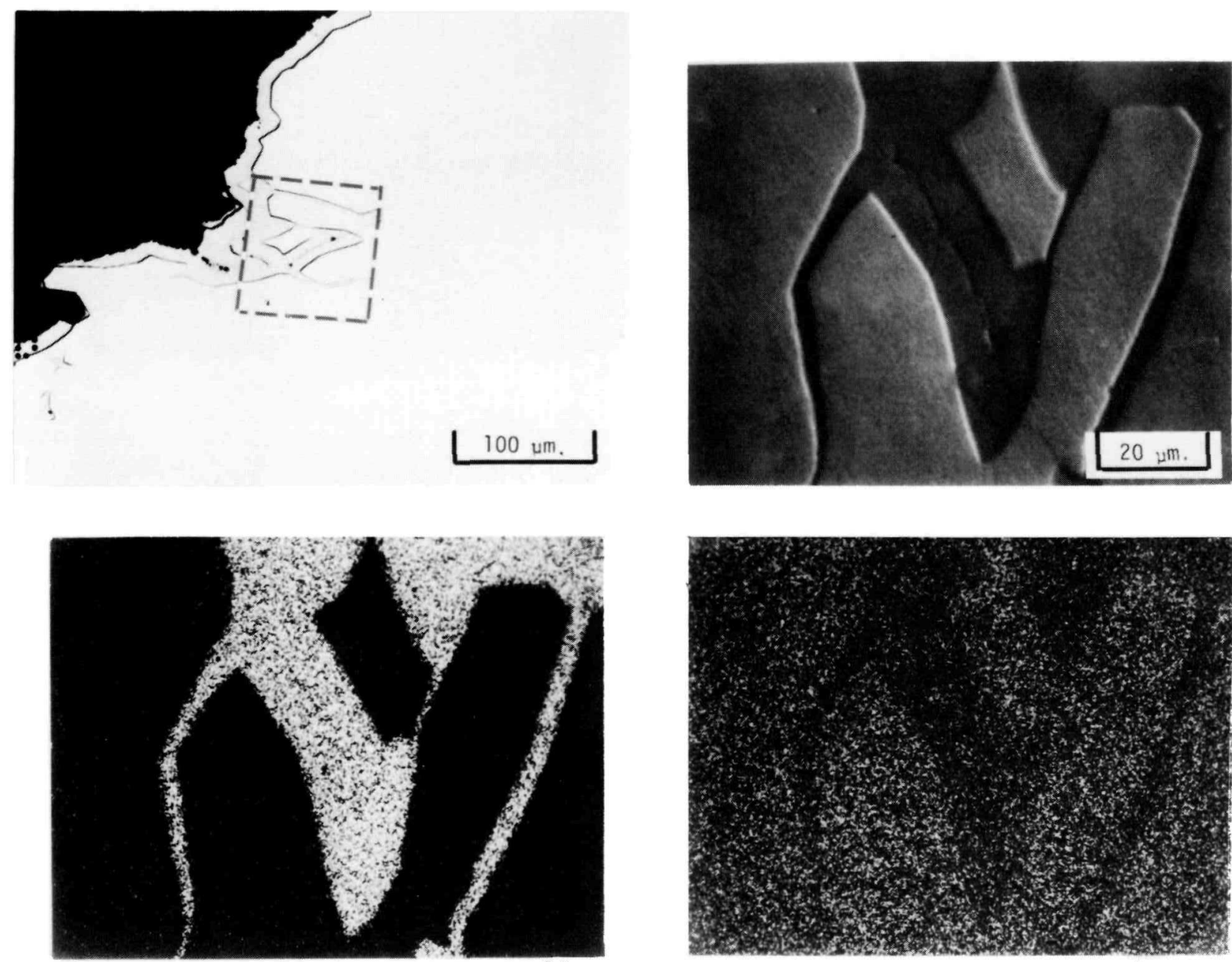

Al

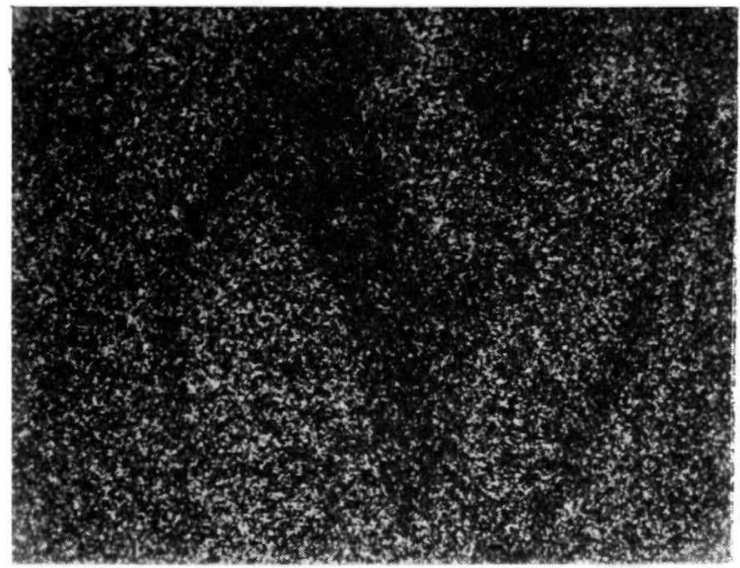

Ir

Fig. 32. EMP analysis of the M-12 intermetallic coating indicated that the principal constituents were aluminum and iridium.

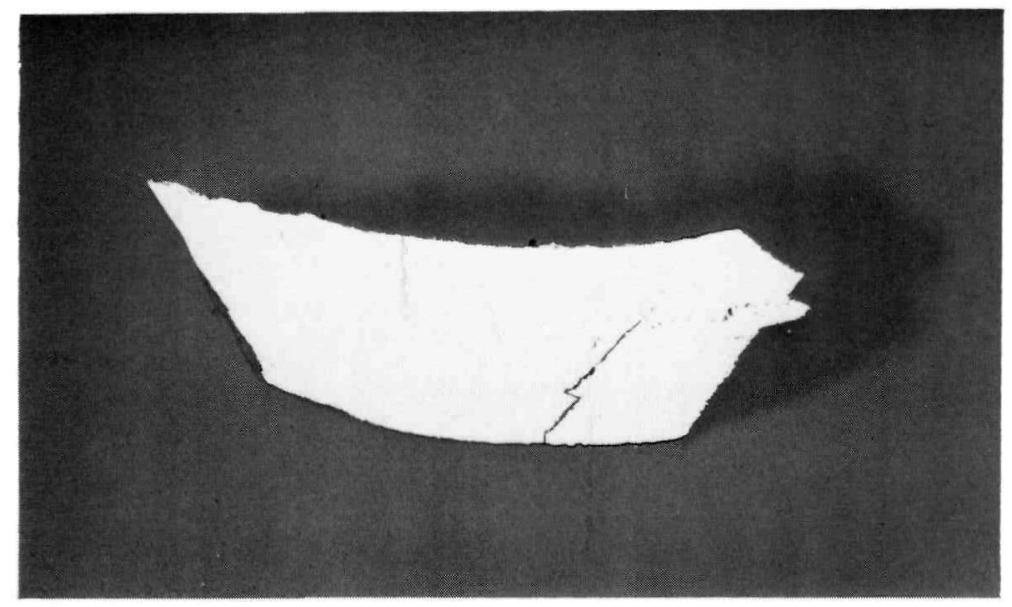

Fig. 33. A fragment of the FPT-3 flyer plate, identified as a portion of the punchout fragment, was metallographically examined; as polished, $7 \mathrm{X}$. 


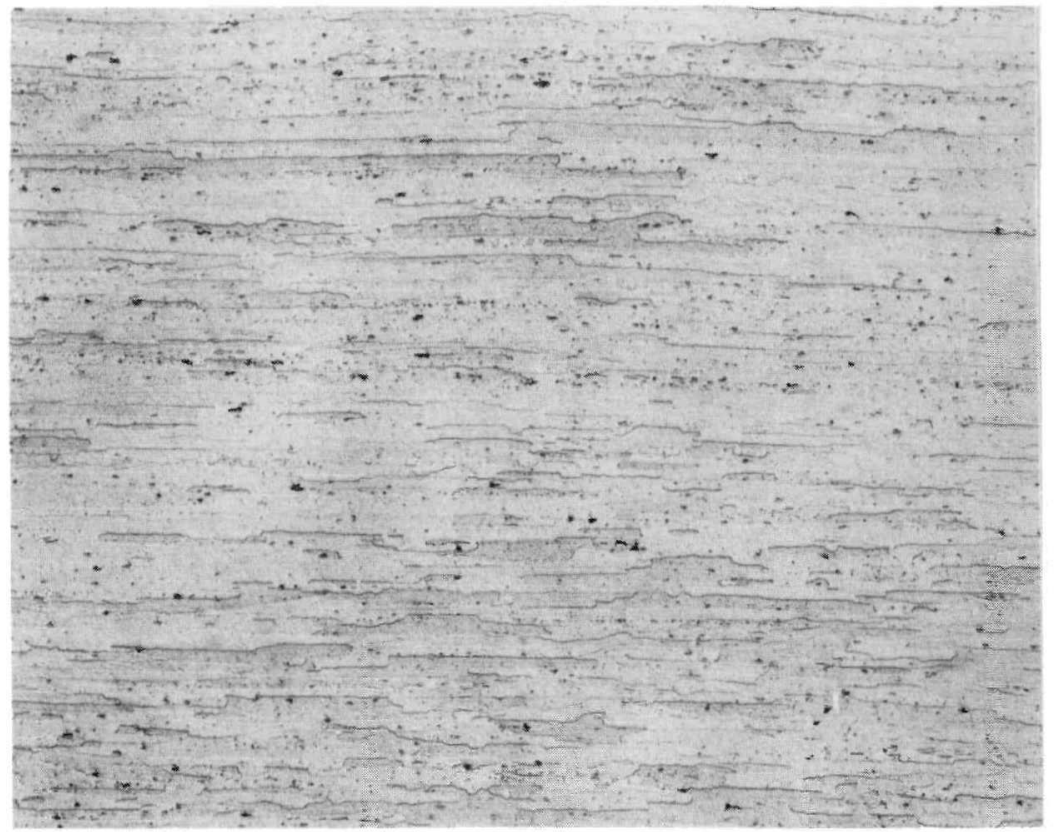

(a)

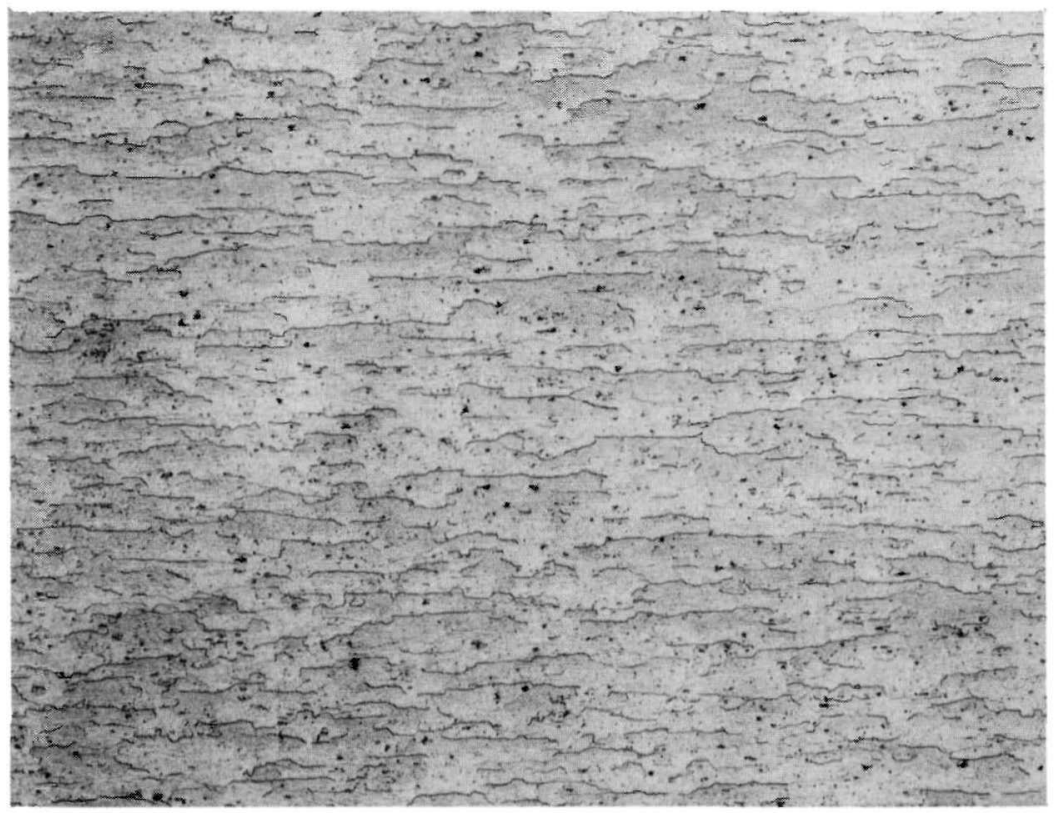

(b)

Fig. 34. Samples taken at the edge of the FPT-3 flyer plate indicate that the rolling direction of the plate was parallel to the M-12 axis at impact. (a) Parallel and (b) transverse; both etched, 50X. 


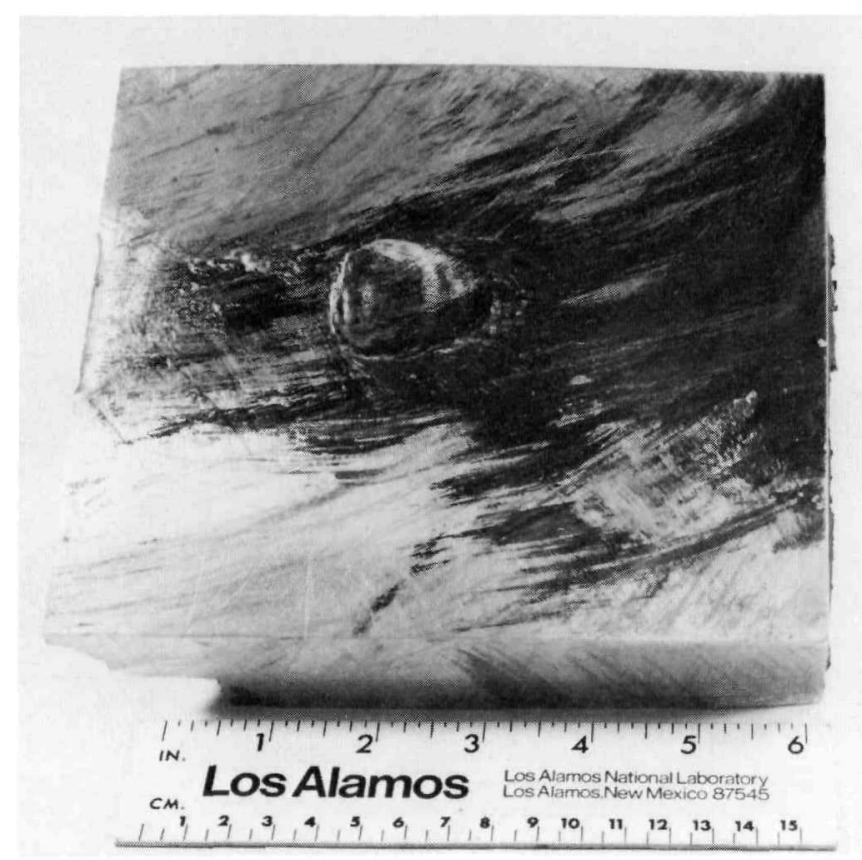

Fig. 35. Clad M-33 indented the 38.1-mm-thick flyer plate to a depth of $4.95 \mathrm{~mm}$ in FPT-4.

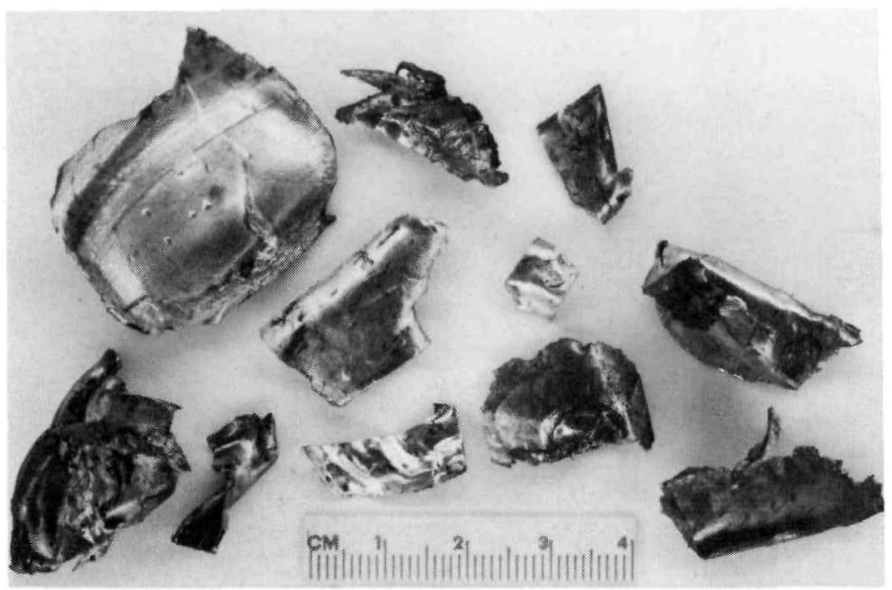

Fig. 36. Clad M-33 was fragmented into 11 pieces when it was struck by a $38.1-\mathrm{mm}$-thick aluminum flyer plate traveling at a velocity of $271.3 \mathrm{~m} / \mathrm{s}$. 


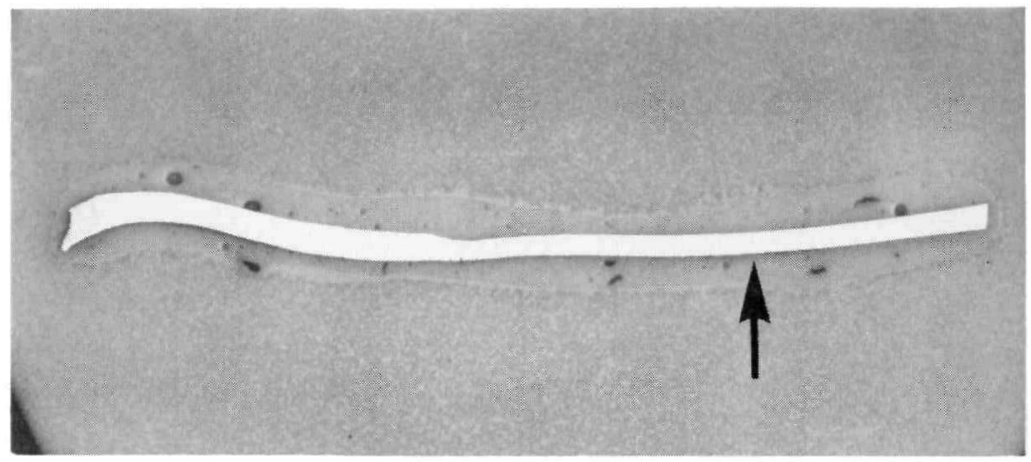

Fig. 37. The largest iridium fragment was identified as being the impact face of clad M-33. The arrow indicates the center of the impact face; as polished, $4 \mathrm{X}$.
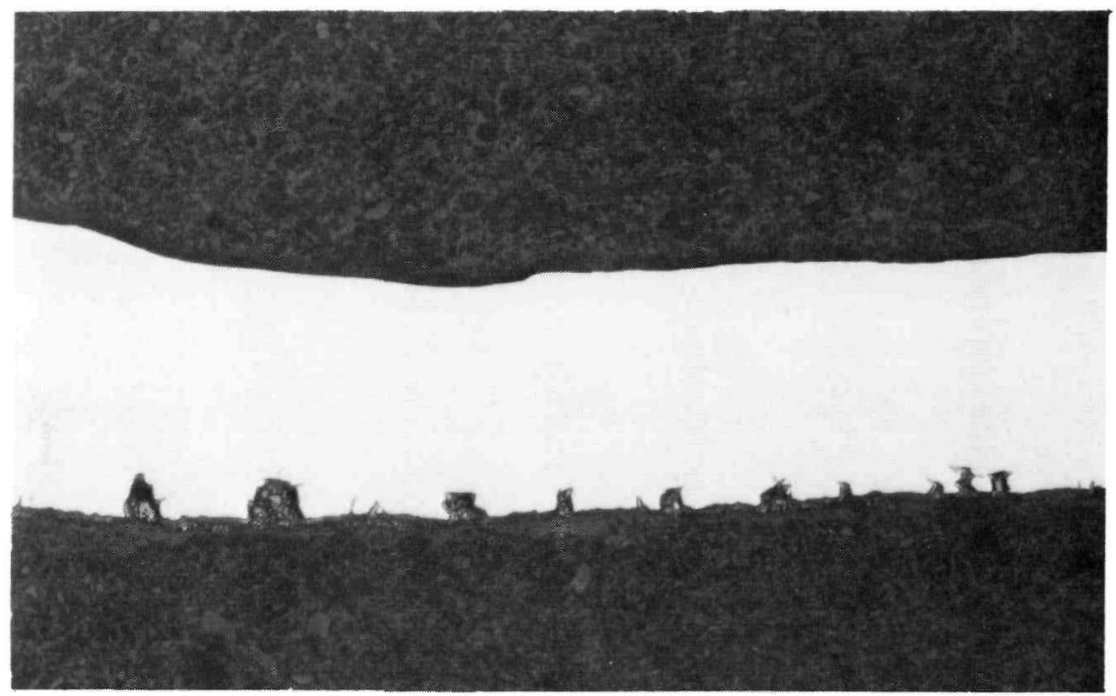

(a)

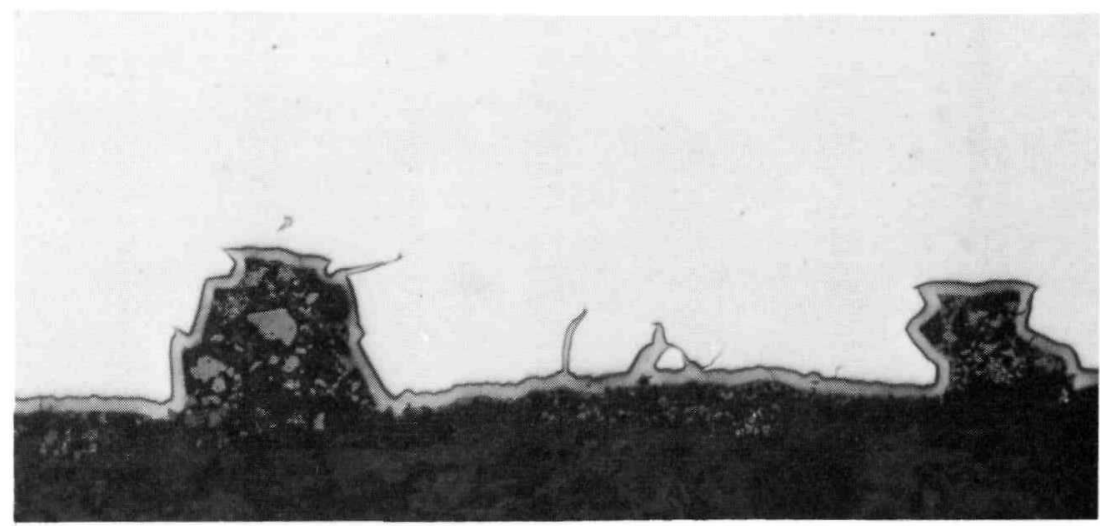

(b)

Fig. 38. An intermetallic coating and a porous, nonmetallic material were observed in the cracks on the exterior of the M-33 impact face; (a) as polished, $50 \mathrm{X}$, and (b) as polished, 200X. 


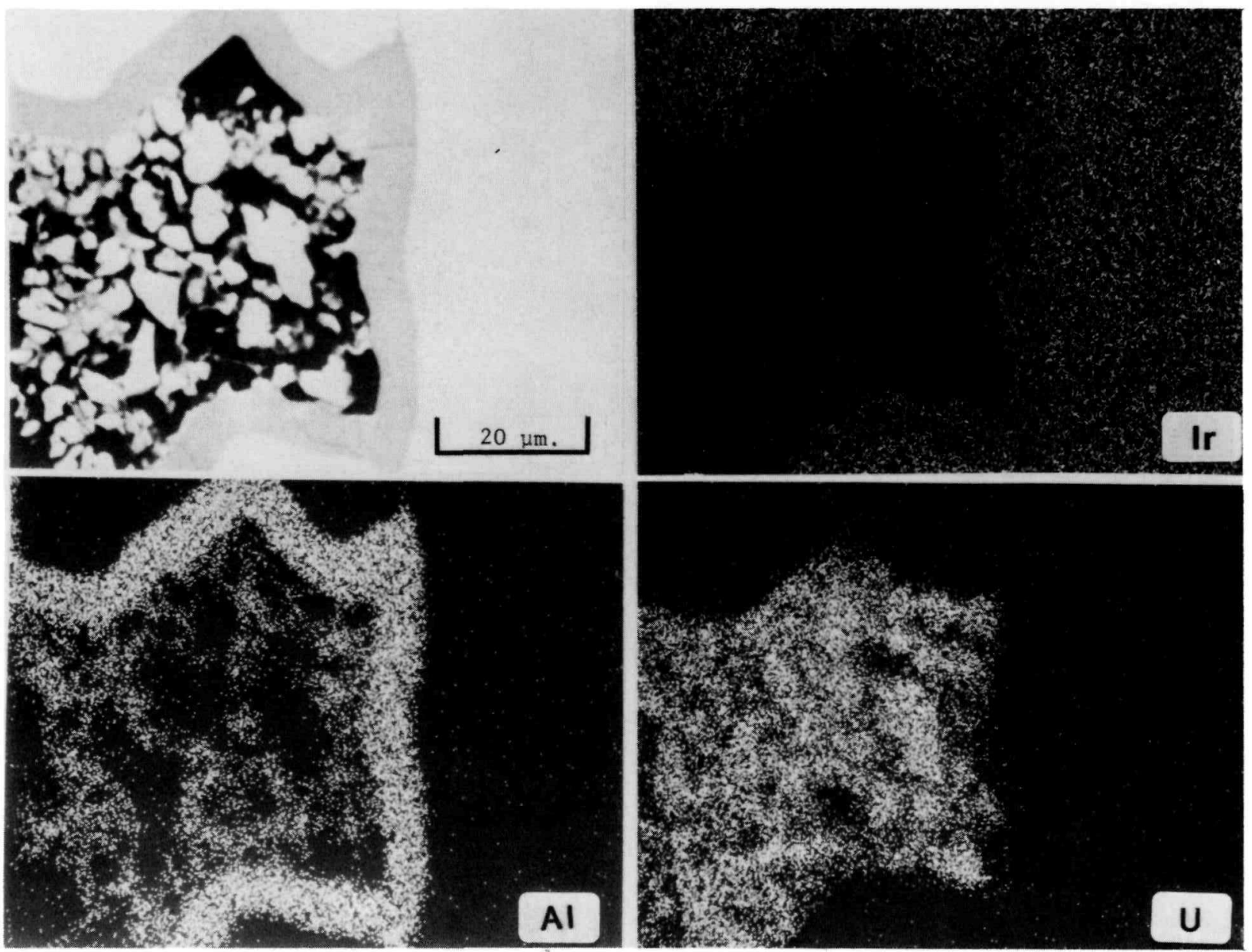

Fig. 39. EMP analysis of one of the M-33 cracks identified aluminum and iridium as the principal constituents of the coating and identified $\mathrm{UO}_{2}$ in the nonmetallic material. 


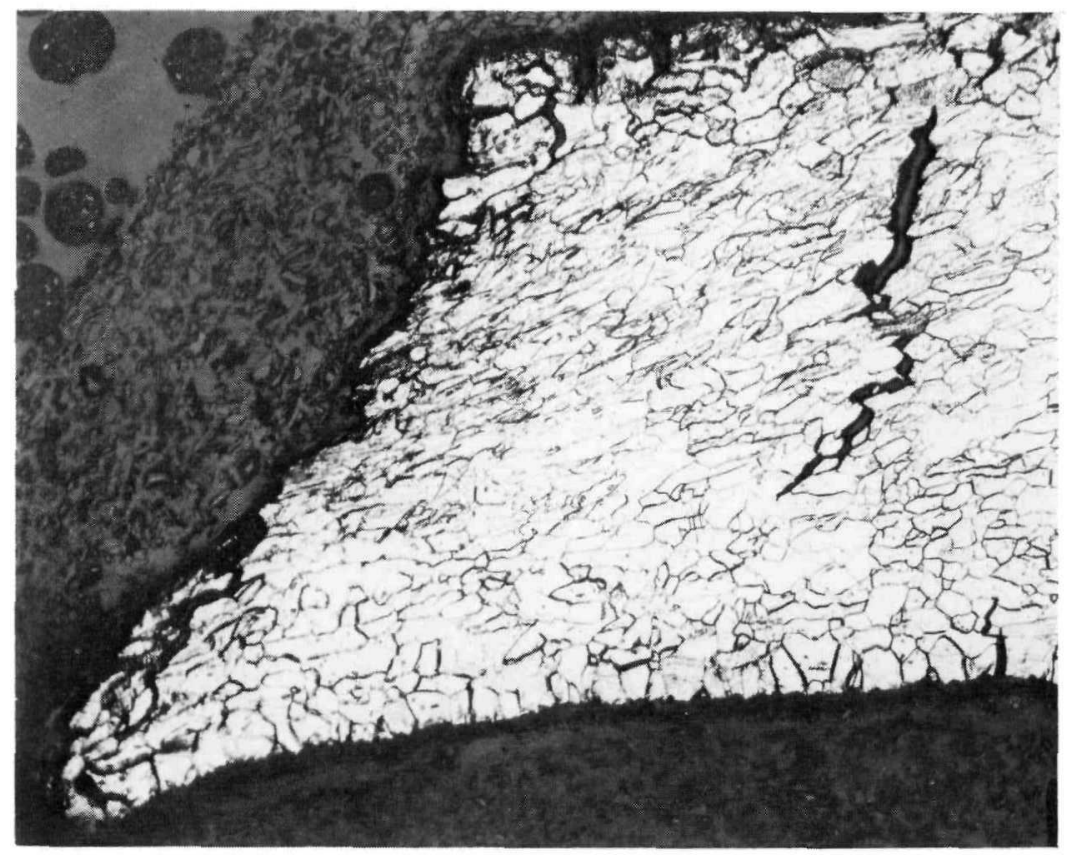

Fig. 40. The edge of the M-33 fragment exhibited characteristics of a ductile fracture and plastic deformation; etched, $80 \mathrm{X}$.

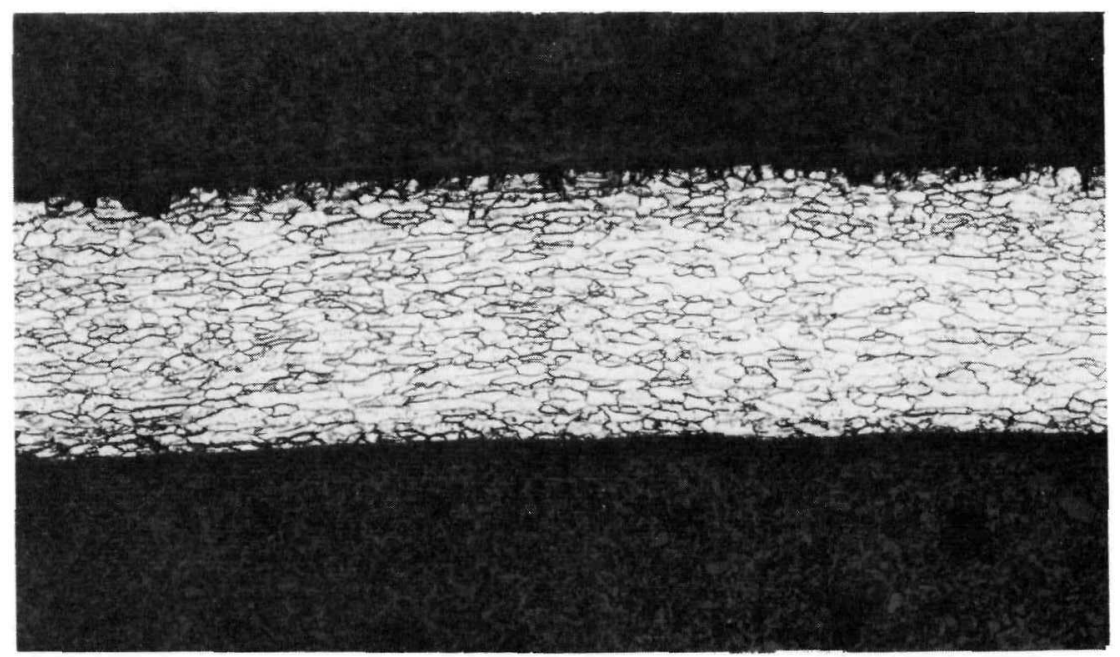

Fig. 41. Extensive elongation of the iridium grains and a $25 \%$ reduction in wall thickness were observed at the center of the M-33 impact face; etched, $50 \mathrm{X}$. 


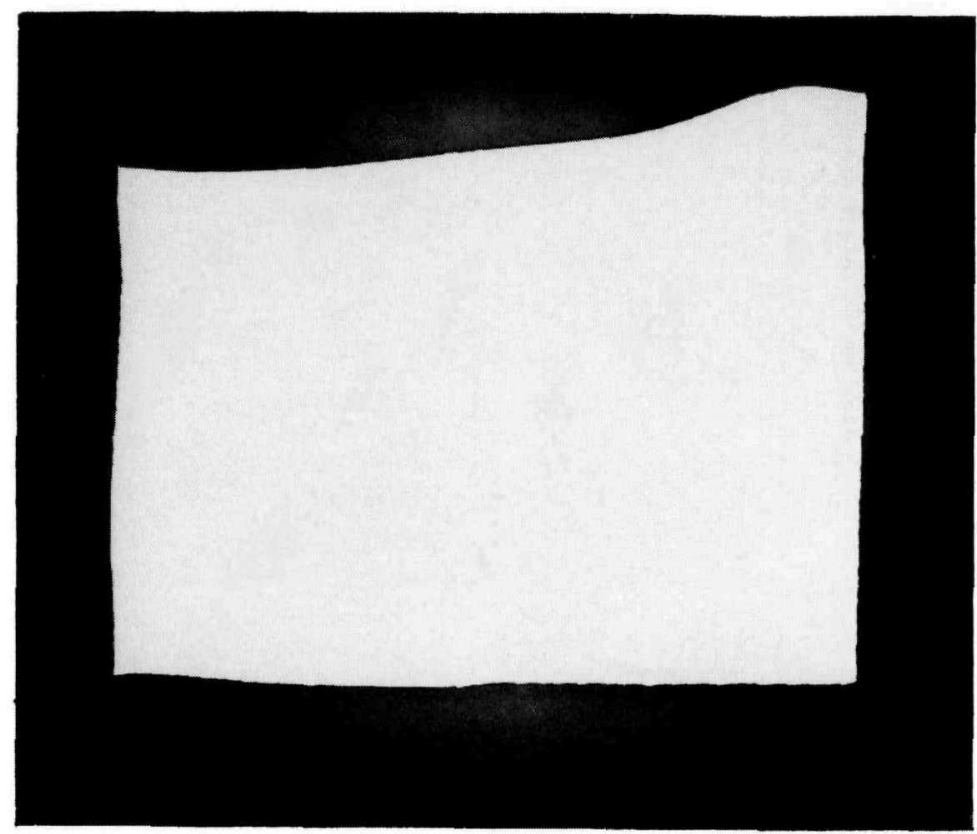

Fig. 42. A portion of the impacted area of the FPT-4 flyer plate was metallographically examined; as polished, $4 \mathrm{X}$.

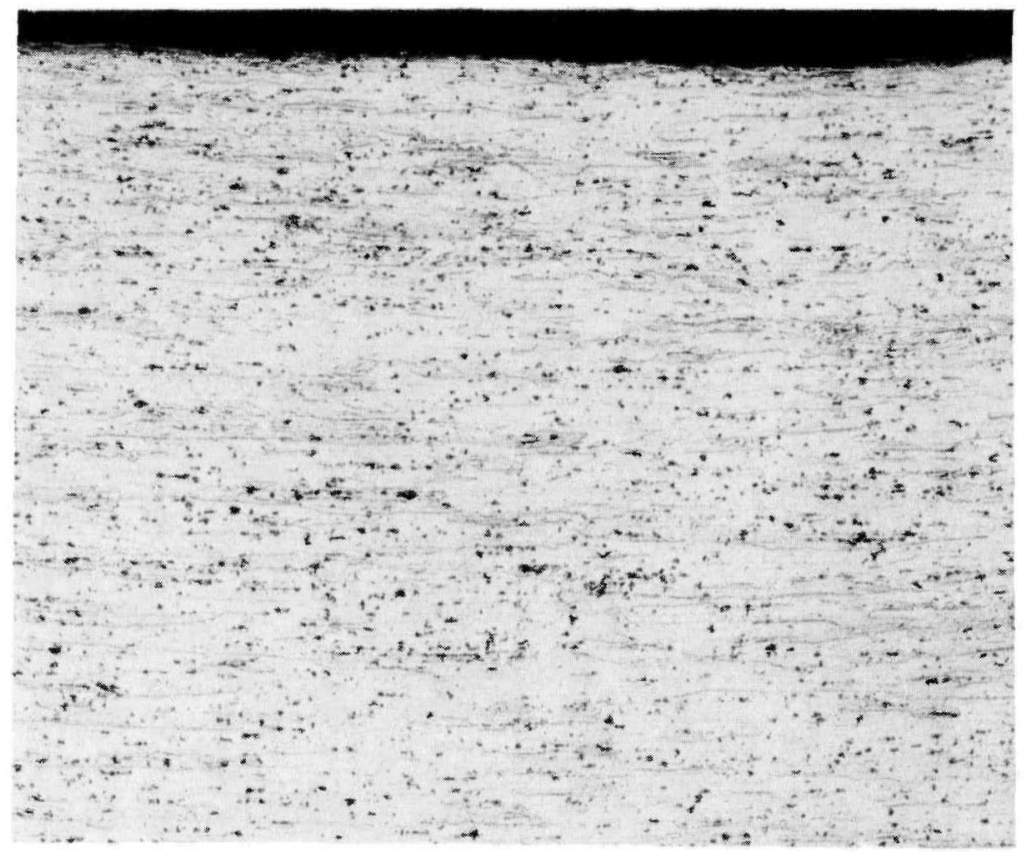

Fig. 43. The iridium grains at the surface of the FPT-4 flyer plate impact area were severely flattened; etched, $50 \mathrm{X}$. 


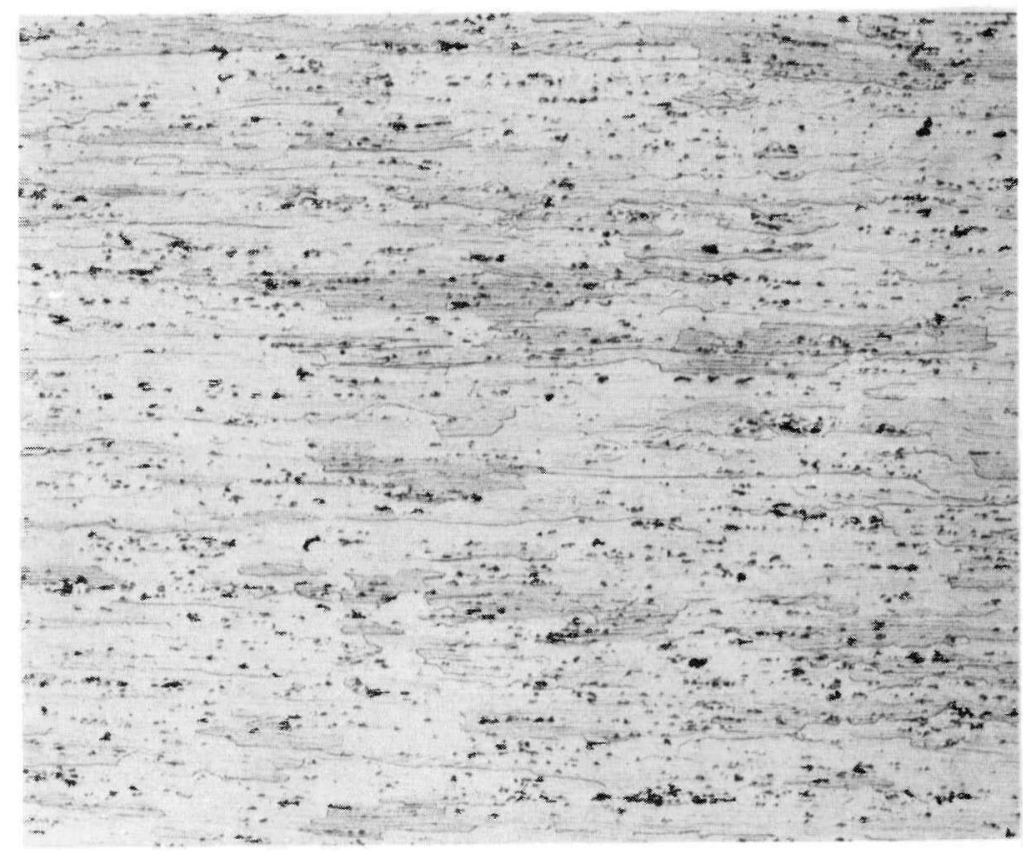

Fig. 44. FPT-4 flyer plate bulk microstructure; etched, 50X. 


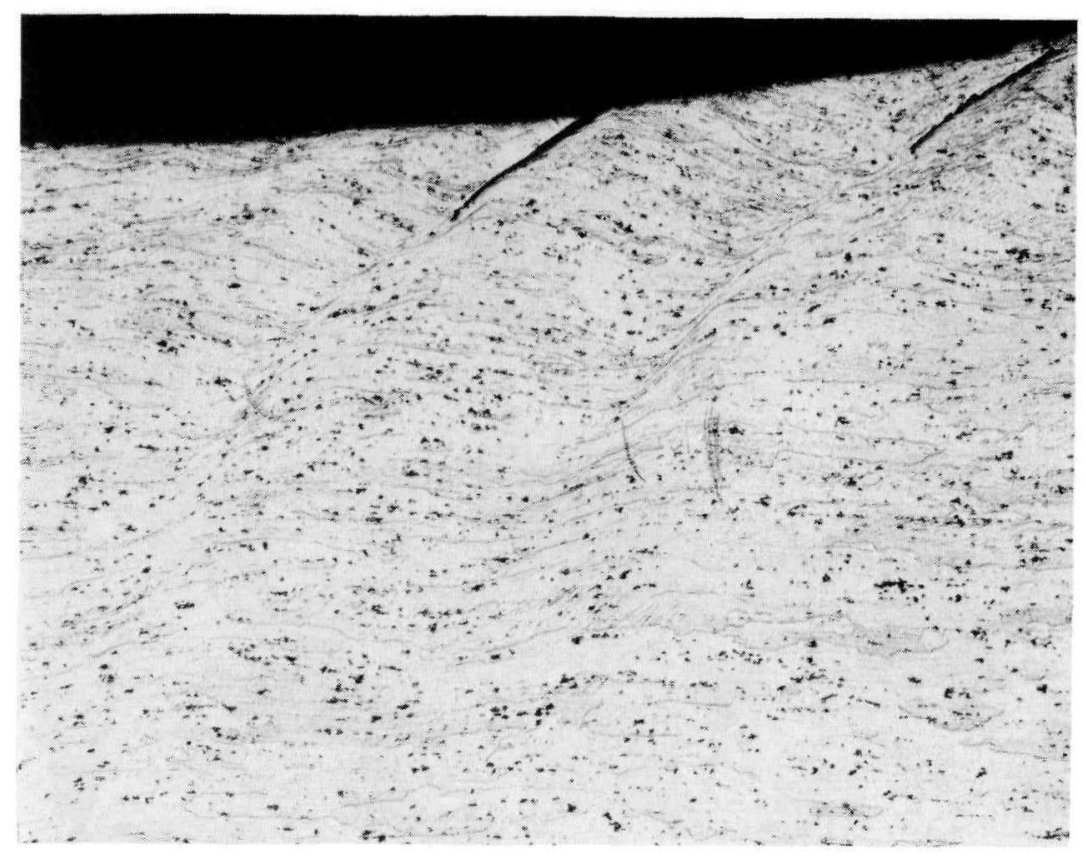

(a)

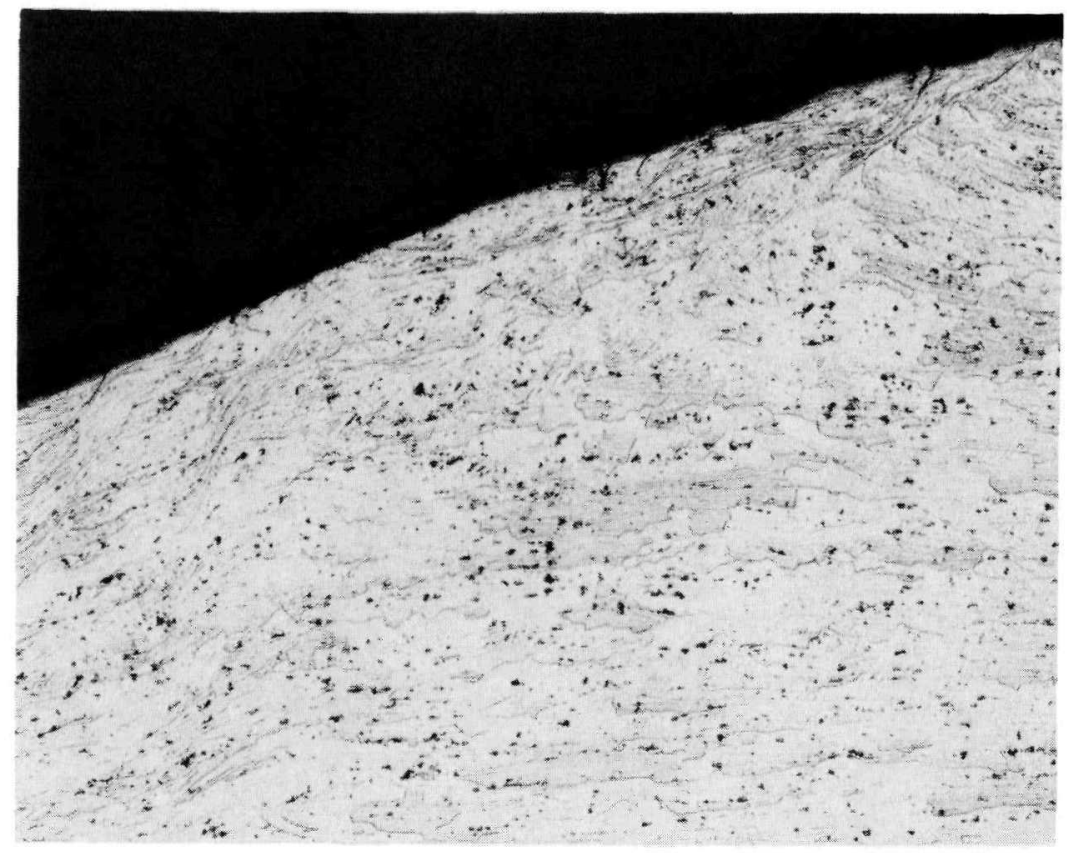

(b)

Fig. 45. Adiabatic shear bands and small fractures were observed near the edge of the plate area impacted in FPT-4; (a) and (b), both etched, 50X. 